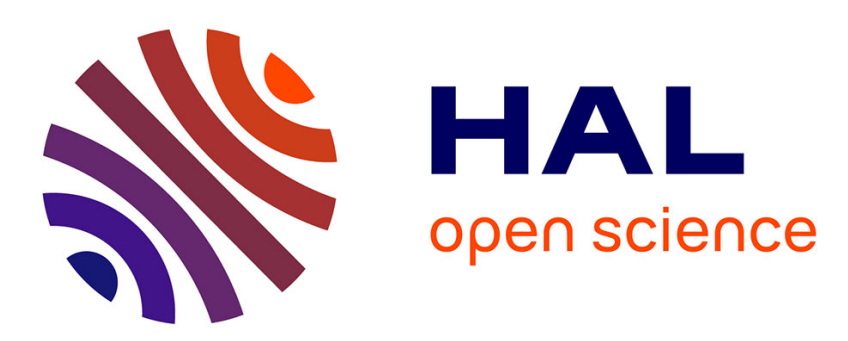

\title{
Acoustic emission monitoring of wet H2S cracking of linepipe steels: Application to hydrogen-induced cracking and stress-oriented hydrogen-induced cracking
}

V. Smanio, Jean Kittel, Marion Fregonese, T. Cassagne, Bernard Normand, F. Ropital

\section{To cite this version:}

V. Smanio, Jean Kittel, Marion Fregonese, T. Cassagne, Bernard Normand, et al.. Acoustic emission monitoring of wet $\mathrm{H} 2 \mathrm{~S}$ cracking of linepipe steels: Application to hydrogen-induced cracking and stressoriented hydrogen-induced cracking. Corrosion, 2011, 67 (6), 10.5006/1.3595097 . hal-01813663

\section{HAL Id: hal-01813663 \\ https://hal.science/hal-01813663}

Submitted on 20 Dec 2019

HAL is a multi-disciplinary open access archive for the deposit and dissemination of scientific research documents, whether they are published or not. The documents may come from teaching and research institutions in France or abroad, or from public or private research centers.
L'archive ouverte pluridisciplinaire HAL, est destinée au dépôt et à la diffusion de documents scientifiques de niveau recherche, publiés ou non, émanant des établissements d'enseignement et de recherche français ou étrangers, des laboratoires publics ou privés. 


\title{
ACOUSTIC EMISSION MONITORING OF WET $\mathrm{H}_{2}$ S CRACKING OF LINEPIPE STEELS: APPLICATION TO HIC AND SOHIC
}

\author{
V. Smanio ${ }^{1}$, J. Kittel ${ }^{2}$, M. Fregonese ${ }^{3}$, T. Cassagne ${ }^{1}$, B. Normand ${ }^{3}$, F. Ropital ${ }^{2}$ \\ 1. Total, ave Larribau F-64018 Pau (France)
}

2. IFP Energies nouvelles, Rond-point de l'échangeur de Solaize - BP3, 69360, Solaize (France)

3. Université de Lyon, INSA-Lyon, MATEIS CNRS UMR 5510, 21 ave J.Capelle F-69621

Villeurbanne (France)

\begin{abstract}
Acoustic emission (AE) was used for monitoring steel cracking during exposure to wet hydrogen sulfide environments. A method for filtering AE data related to hydrogen induced cracking (HIC) was presented, and applied for several case studies.

In a series of tests on unstressed sweet service steels, evolution of $\mathrm{AE}$ indicated three successive HIC phases. An initial incubation period corresponded to hydrogen entry in the steel, during which no cracking occurred. Then two cracking phases were detected. The first was associated with decohesion of weak steel interphases. The second was identified as crack propagation under high internal hydrogen pressure. Crack propagation decreased and eventually ceased over time.

Analysis of $\mathrm{AE}$ data was then used to evaluate the extent of $\mathrm{HIC}$ after sour exposure. Correlation was found when appropriate data filtering was applied.

AE analysis was also applied to sour service steels under an applied load. The first steel exhibited HIC AE signals. Its fracture surface was typical of a stress oriented hydrogen induced cracking (SOHIC) mode of failure, in good agreement with AE results. For the second steel,
\end{abstract}


which also failed during the test, no AE related to HIC was detected. Fracture surface was typical of sulfide stress cracking (SSC), also in good agreement with AE findings.

Keywords: Hydrogen embrittlement, HIC, SSC, SOHIC, low alloy steel, acoustic emission 


\section{INTRODUCTION}

In oil and gas production environments, the presence of acid gases and water can induce severe corrosion of carbon and low alloy steels. In addition to potentially rapid uniform corrosion in sour environments, hydrogen embrittlement phenomena can occur. In the presence of hydrogen sulfide $\left(\mathrm{H}_{2} \mathrm{~S}\right)$, hydrogen atoms originating from the electrochemical reduction of protons can diffuse into the steel, and induce cracking. Depending on the steel type and on the mechanical loading, different forms of cracking can occur, the most common being hydrogen-induced cracking (HIC), stress-oriented hydrogen induced cracking (SOHIC), and sulfide stress cracking (SSC) as defined in NACE MR0175/ISO 15156-1 ${ }^{1}$ standard.

The selection of appropriate steel grades for a given application therefore requires adequate qualification procedures, to ensure a high level of safety for the equipment. $\mathrm{H}_{2} \mathrm{~S}$ cracking standard tests are listed in NACE MR0175/ISO 15156-2 $2^{2}$ standard, and described in details in EFC 16 publication $^{3}$, NACE TM $0284-2003^{4}$, NACE TM $0177-96^{5}$ or refining ${ }^{6}$ standard.

In the specific case of HIC, standard practice consists in 96 hours exposure in a test solution (which composition is defined in the above standards) saturated with 1 bar $\mathrm{H}_{2} \mathrm{~S}$, with $\mathrm{pH}$ ranging from 2.6 to 4 .

Full sour resistance is not always necessary. In less severe environments, i.e. of higher $\mathrm{pH}$ and/or lower $\mathrm{H}_{2} \mathrm{~S}$ partial pressure $\left(\mathrm{pH}_{2} \mathrm{~S}\right)$, steel grades with intermediate resistance might still be appropriate. In such cases, standard HIC tests can be too severe to qualify materials. Fitfor-purpose (FFP) testing methodologies must then be used, to ensure adequacy between steel resistance and field conditions. Unfortunately, the methodology for HIC FFP testing is not well identified in testing standards. The lower $\mathrm{pH}_{2} \mathrm{~S}$ limit below which an assessment of $\mathrm{HIC}$ resistance is unnecessary is also not yet elucidated.

In the last years, work was done to better defining $\mathrm{HIC}$ regions of environmental severity, and to propose adapted FFP testing procedures to safely select sweet service steel grades for use in mildly sour environments ${ }^{7}$. Initial results showed that long exposure tests were required for testing under low $\mathrm{H}_{2} \mathrm{~S}$ partial pressure, i.e. more than 1 month under 10 mbar 
$\mathrm{H}_{2} \mathrm{~S}$ or below. Furthermore, no $\mathrm{H}_{2} \mathrm{~S}$ lower threshold was found, since HIC was found on some steels after 3 months testing under 3 mbar $\mathrm{H}_{2} \mathrm{~S}$. This program is still ongoing, but it highlights the need to better understand HIC mechanisms, especially in mildly sour environments.

In order to keep improving FFP testing procedures and to help better select HIC FFP resistant steels, a better understanding of the HIC process seems necessary. In this regard, standard HIC tests as well as conventional FFP experiments consisting of metallographic examination after exposure do not reveal cracking mechanisms in sufficient detail. Additional experimental techniques may help and the use of continuous real-time monitoring methods appears to be particularly relevant. In a recent study, the authors used hydrogen permeation experiments, and showed some correlations with HIC degradation ${ }^{8}$. In particular, modeling of hydrogen accumulation in the steel enabled prediction of the time necessary for HIC to occur. In another study, acoustic emission (AE) was used to monitor steels behavior in $\mathrm{H}_{2} \mathrm{~S}$ environments $^{9-10}$. One of the main issues was an identification of different $A E$ physical sources, with HIC cracking giving rise to $A E$ events with specific features. The aim of the present study is to apply this AE methodology to investigate in more details HIC.

\section{LITERATURE BACKGROUND}

$A E$ technique is a non-destructive evaluation method allowing the detection of active defects within materials in real time during the test. Each active defect gives rise to elastic waves which propagate into the material and results in detectable AE signals. The typical shape of $A E$ wave is presented in Figure 1. From this signal, several parameters can be extracted. In the time domain, the most common parameters are the signal peak amplitude, its duration, the number of counts. The energy of the signal, calculated as the integral of the absolute value of the signal, is also often considered for $A E$ analysis. Other parameters can be calculated in the frequency domain after Fourier transform. Each AE event can be described by a set of parameters. The first level of $A E$ analysis then consists in trying to relate each $A E$ 
event to a given type of physical source. All AE events presenting parameters in the same range can then be grouped for further analysis. The second level of $A E$ analysis consists in following $\mathrm{AE}$ emissions during a certain period of time. With that aim, it is common practice to calculate the total amount of some specific signals, i.e. cumulative energy or cumulative number of events.

Figure 1: Typical AE waveform and characteristic parameters.

Good correlations were obtained between specific AE parameters and amplitude of corrosion damage in various cases: stress corrosion cracking ${ }^{11-13}$, abrasion or erosion corrosion ${ }^{14}$, pitting corrosion ${ }^{15-17}$, crevice corrosion ${ }^{18-19}$, exfoliation corrosion ${ }^{20}$, and uniform corrosion in acid media ${ }^{21}$. Among the variety of mechanisms of deformation and damage that can generate $\mathrm{AE}$, corrosion processes take a particular position. In such cases, the source of acoustic emission is often not the electrochemical corrosion driving force itself, but its consequence: bubble formation, crack propagation and modifications in corrosion products or deposits ${ }^{11-22}$, depending on whether corrosion is localized or uniform.

The AE technique was also applied to monitor $\mathrm{H}_{2} \mathrm{~S}$ cracking in several studies ${ }^{23-28}$. Cayard et al. ${ }^{25}$ and also Gingell et al. ${ }^{27}$ showed that during stress corrosion tests leading to the failure of the specimen, a higher rate of increase of the AE cumulative energy was recorded compared to no-failure tests. The critical rate associated with SSC failure remained dependant on the tested steels and the applied stress level. Weng et al. ${ }^{24}$ found a correlation between HIC damage and the AE cumulative energy. Moreover, Gingell et al. ${ }^{27}$ showed that AE could be used to discriminate initiation and propagation stages of cracking during NACE TM0177-96 5 method $A$ tensile tests. However, in all these studies, AE data were treated in a global manner, i.e. considering simultaneously all the $\mathrm{AE}$ sources involved during the test. Therefore, a large amount of "background noise", i.e. AE data generated by other physical sources than HIC, SOHIC or SSC cracking was included in the data. 
More recently, the present authors proposed a new approach for the treatment of $A E$ data obtained through $\mathrm{H}_{2} \mathrm{~S}$ cracking experiments ${ }^{9-10}$. First, a detailed analysis of $A E$ events detected during exposure of steels in wet $\mathrm{H}_{2} \mathrm{~S}$ media was performed. The goal of this analysis was to link each $\mathrm{AE}$ event to the physical process by which it was generated. It was shown that three major physical sources could contribute to generate acoustic emission:

- Nucleation and growth of iron sulfide scale on steel surfaces,

- Nucleation of $\mathrm{H}_{2}$ bubbles at the steel surface, following the proton reduction,

- Steel cracking, due to $\mathrm{H}$ absorption and diffusion in the steel

Then, it was shown that the analysis of the energy and duration of each AE event allowed linking it with one of these physical sources, as illustrated in Figure 2.

Figure 2: Representation of AE events in energy as a function of signal duration, used to link each $A E$ event to its physical source (experimental data from exposure test on X65 sweet service steel in EFC16 test solution at $\mathrm{pH} 4.5$ and under 1 bar $\left.\mathrm{H}_{2} \mathrm{~S}\right)^{9}$.

For the given experimental configuration (specimen geometry, AE system set-up, etc), HIC signals were discriminated from the others using the criterion that all $A E$ signals with duration above $1500 \mu$ s were attributed to cracking. AE analysis was then made using only these data, clearly associated with HIC, all other contributions being filtered out.

In the present study, the above methodology is applied to compare the evolution of HIC with exposure time for three different sweet service steels. Then, a preliminary attempt to correlate the extent of HIC with AE parameters is investigated. Finally, another application is proposed for the analysis of stress cracking under $\mathrm{H}_{2} \mathrm{~S}$ exposure, and a clear distinction between SSC and SOHIC is evidenced. 


\section{EXPERIMENTAL}

\section{Tested Materials}

Five steels with various $\mathrm{H}_{2} \mathrm{~S}$ cracking susceptibility were selected for the experimental program: three sweet service grades $(\mathrm{X} 60, \mathrm{X} 65$ and $\mathrm{X} 70)$ and two sour service grades (X65 and C110). For all materials, the microstructure was observed using an optical microscope, after polishing with a $0.05 \mu \mathrm{m}$ finishing suspension and etching with a $2 \%$ Nital (nitric acid ethanol) solution. The microstructures at the mid wall location are presented in Figure 3 to Figure 7. The chemical compositions of all steels (Table 1) were analyzed by optical emission spectrometry (OES), except for carbon and sulfur which were analyzed by a chemical method.

The main characteristics of the microstructure of these steels are the following:

- Sweet service X60 (HSAW pipe, $14.2 \mathrm{~mm}$ thick, coming from thermomechanical rolled hot strip) presents two phases: ferrite and pearlite. The microstructure is highly orientated in the rolling direction, with a segregation zone in the midthickness,

- Sweet service X65 (LSAW pipe, $25 \mathrm{~mm}$ thick, from thermomechanical controlled heavy plate) presents a typical ferrite - pearlite microstructure, which is highly orientated in the rolling direction,

- Major phases observed in sweet service X70 (14.2 mm thick sheet, from thermomechanical rolled hot strip) are ferrite and a small proportion pearlite. The microstructure is highly orientated in the rolling direction, with a thin segregation area in the mid-thickness,

- Sour service X65 (20 mm thick hot rolled plate) also presents ferrite and pearlite as major phases. However, contrary to sweet grades, the microstructure is more equiaxed and homogeneous, which accounts for its good HIC resistance,

- C110 sour grade (seamless pipe, $21 \mathrm{~mm}$ thick) is a tempered martensite. 
Table 1: Chemical composition (wt \%) of tested steels (bal. Fe).

Figure 3: Microstructure of the X60 sweet service grade (LT plane).

Figure 4: Microstructure of the X65 sweet service grade (LT plane).

Figure 5: Microstructure of the X70 sweet service grade (LT plane).

Figure 6: Microstructure of the X65 sour service grade (LT plane).

Figure 7: Microstructure of the C110 sour service grade (LT plane).

\section{Test specimens}

Different geometries of test specimens were used.

The most common type consisted in standard tensile specimens described in NACE TM0177- $96^{5}$ method A for SSC testing. The gauge section of the tensile specimen was 6.35 $\mathrm{mm}$ in diameter and $25.4 \mathrm{~mm}$ in length. All specimens were machined from the mid-wall thickness, parallel to the rolling direction. Both heads of the tensile probes were designed to allow the used of acoustic emission sensors. Only the gauge section was exposed to the test solution. The probe geometry was chosen as a standard reference for this study which was part of a program devoted to HIC, SOHIC and also SSC. Therefore, all types of cracking could be studied by acoustic emission without changing experimental setup and probes geometries, SOHIC and SSC being studied by applying a constant load (proof ring), while HIC experiments was studied without external loading.

For some experiments aimed at evaluating the extent of HIC cracking by acoustic emission, specific specimens were machined. Their geometry was based on SSC tensile specimens, 
where the cylindrical gauge section was replaced by a square section $(50 \mathrm{~mm}$ in the rolling direction, $20 \mathrm{~mm}$ wide). The thickness of the specimen is the same as the bare steel. This shape is typical of HIC test specimens of NACE TM0284-2003 ${ }^{4}$. The major advantages of this geometry were:

- Exposure in the same test vessels as standard SSC tests,

- Easy AE monitoring,

- More representative of usual HIC NACE TM 0284-2003 ${ }^{4}$ standard tests,

- Easy evaluation of HIC through ultrasonic inspection.

Only the square section was exposed to the test solution.

\section{Exposure conditions and acoustic emission measurements}

The experimental set up (Figure 8) was based on the standard tensile test described in NACE TM0177-965 (method A). For HIC tests, no load was applied to the test specimens. For SSC and SOHIC, a constant load was applied with the proof ring, corresponding to $90 \%$ of the steel yield strength (YS).

Only the gauge section of the specimen was immersed in the corrosive solution.

Test solutions were prepared according to EFC16 recommendations ${ }^{3}$ (solution A), and thus contained $50 \mathrm{~g} / \mathrm{L}$ sodium chloride and $4 \mathrm{~g} / \mathrm{L}$ sodium acetate, with pure $\mathrm{H}_{2} \mathrm{~S}$ as test gas.

After a thorough deaeration with nitrogen, the solution was saturated by bubbling gas at ambient pressure. The $\mathrm{pH}$ was then adjusted to the desired value through addition of deaerated $1 \mathrm{~N}$ hydrochloric acid or $1 \mathrm{M}$ sodium hydroxide $\mathrm{NaOH}$.

Test solution was then circulated from the separate vessel to the test cell. This circulation was maintained throughout all the experiment. Indeed, this procedure allowed to avoid any interfering $\mathrm{AE}$ noise detection (e.g. gas bubbling in the test cell would result in $\mathrm{AE}$ ) and to easily control and adjust the $\mathrm{pH}$ to desired value.

Figure 8: Experimental set-up for $A E$ measurements of $\mathrm{H}_{2} \mathrm{~S}$ exposure tests, with or without applied load. 
$A E$ measurements were performed using two $A E$ sensors placed at the top and bottom of the specimen (Figure 8). The AE instrumentation consisted of a transducer, a preamplifier and an acquisition device (MISTRAS ${ }^{*}$ or PCI2 card, with $\mathrm{AEWIN}^{\star}$ software). Frequency range of the AE sensors was $150-400 \mathrm{kHz}$. $40 \mathrm{~dB}$ pre-amplification was used, and all signals below a constant $28 \mathrm{~dB}$ threshold were discarded. A more detailed description of $A E$ system settings is given elsewhere ${ }^{9-10}$.

\section{Analysis of cracks at the end of exposure tests}

Different methods were used for the examination of specimens after testing.

The primary methodology applied to evaluate HIC extent consisted in sectioning the specimens in three equidistant cuts, followed by metallographic examination of the crosssections, as described in NACE TM0284-2003 ${ }^{4}$.

HIC was also examined by immersion ultrasonic inspection with a $15 \mathrm{MHz}$ transducer (1/4" diameter). The system was calibrated according to an in-house technique. For each specimen, the total area of the defects was calculated from the ultrasonic (US) scans, and the crack area ratio (CAR) was determined as the ratio of the area of the defects over the total area of the specimen in the short transverse plan.

For SSC and SOHIC tests leading to failure of the specimen, the fracture surfaces were examined with a scanning electron microscope.

\footnotetext{
"MISTRAS and AEWIN are trade names from Mistras Group Inc., Princeton Junction, NJ (USA)
} 


\section{RESULTS AND DISCUSSION}

\section{Comparison of HIC susceptibility of three different sweet service steels}

First, HIC experiments were performed at $\mathrm{pH} 4.5$ and 1 bar $\mathrm{H}_{2} \mathrm{~S}$ for the different sweet service steels. AE data obtained during a 96 hours exposure for each steel type are compared in Figure 9. Using this representation, and for the given experimental set-up (specimen geometry, AE system set-up, etc), AE events related to HIC have a typical duration higher than $1500 \mu \mathrm{s}^{9-10}$. According to this criterion, HIC was expected for all three steels during these tests. However, when comparing more closely Figure 9 for the different steels, some qualitative differences are noted: the total number of $\mathrm{AE}$ events related to $\mathrm{HIC}$ does not look the same, neither the duration and energy borders of the "HIC domain". This suggests that cracking was not strictly identical for these three steels. In order to investigate this point in more details, metallographic cross section examinations were performed for the three specimens of Figure 9. Typical cross-section views including all observed cracks are presented in Figure 10. Indeed these micrographs confirm the different cracking behaviour of the three steels. X60 and X65 display a succession of small cracks, some of them being connected. In this respect, this type of cracking is typical of stepwise cracking (SWC). The appearance of cracks in X70 is quite different: only one or two large cracks are observed. These cracks are localised at the centre line, where a thin planar segregation area was observed (Figure 5). These observations can be correlated with AE data in Figure 9: HIC related $A E$ data for $X 60$ and $X 65$ look alike, so does cracking appearance for both steel types (SWC). On the other hand, the X70 steel presents a smaller number of cracks, while the HIC region of $A E$ data is more elongated and contains fewer events.

Figure 9: $\mathrm{AE}$ data obtained during 96 hours exposure tests at $\mathrm{pH} 4.5$ and under 1 bar $\mathrm{H}_{2} \mathrm{~S}$ for three different sweet service steels $(X 60, X 65, X 70)$. Separation of $A E$ data related to HIC. 
Figure 10: Aspect of HIC cracks for different sweet service steels (X60, X65, X70) after 96 hours exposure at $\mathrm{pH} 4.5$ under 1 bar $\mathrm{H}_{2} \mathrm{~S}$.

$A E$ data was also filtered ${ }^{9-10}$ in order to analyse only the $A E$ events related to HIC. For all three experiments, cumulative energy of $\mathrm{AE}$ events related to $\mathrm{HIC}$ was plotted as a function of exposure time (Figure 11).

Figure 11 : Comparative evolution of cumulative energy of $A E$ events related to $\mathrm{HIC}$ for tests on different sweet service steels (X60, X65 and X70) at pH 4.5 and under 1 bar $\mathrm{H}_{2} \mathrm{~S}$.

These graphs present some common trends: in particular, they all show an initial period with hardly any $\mathrm{AE}$ events related to $\mathrm{HIC}$, followed by a period with some intense HIC activity, which finally ceases after a sufficient exposure time.

However, some differences between $X 60$ and $X 65$ on the one hand, and X70 on the other hand are also emphasized. For the first two steels, the evolution of AE related to HIC consists of some discrete energy jumps, followed by some continuous increase. The number of sharp rises is higher for the $\mathrm{X} 65$ steel, which presents a smaller number of main cracks as compared to the $\mathrm{X} 60$. For the $\mathrm{X} 70$, this aspect is even more marked: more than $95 \%$ of $\mathrm{AE}$ data related to HIC appeared at the same time, approximately after 40 hours of exposure.

From the correlation between $\mathrm{AE}$ cumulative energy and the cross section micrographs and, the known cracking behaviour the following cracking mechanism for HIC is proposed:

- The initial incubation period corresponds to hydrogen diffusion in the steel, and accumulation at weak interfaces. No detectable $A E$ related to cracking is measured during this period.

- At the end of this incubation period, when the critical hydrogen level is reached, hydrogen precipitates at weak interfaces and decohesion occurs. This 
corresponds to the very first stage of cracking, which is probably of brittle nature. $\mathrm{AE}$ events corresponding to this brittle fracture appear as discrete jumps, with an energy level correlated with the size of the crack.

- When an initial crack is present in the steel, gaseous hydrogen accumulates in the blister until the pressure becomes sufficient to induce crack growth. This propagation is probably micro-ductile or also brittle, and the related EA continuously increases.

- Finally, cracks cease to propagate. Multiple causes can be thought, e.g. if hydrogen activity does not reach a sufficiently high level to induce a gas pressure higher than the mechanical properties of the material, or if hydrogen activity decreases due to hydrogen escape via surface cracks.

This cracking mechanism is in good agreement with current understanding ${ }^{29}$.

\section{Evaluation of the extent of HIC by acoustic emission}

For this part of the study, a series of HIC experiments with different exposure times were carried out at $\mathrm{pH} 4.5$ and 1 bar $\mathrm{H}_{2} \mathrm{~S}$. For each experiment, three conventional (NACE TM 0284-2003 ${ }^{4}$ ) HIC specimens of $100 \mathrm{~mm}$ length and $20 \mathrm{~mm}$ width, and one specimen with a square gauge section equipped with $\mathrm{AE}$ sensors were tested.

After each test, all specimens were examined by ultrasonic inspection. Examples of US scans are presented in Figure 12 in a two-dimensional view (C-scan view), where the color scale corresponds to the depth of the crack. From US scans, CAR was calculated. The evolution of CAR with exposure time is presented in Figure 13. First HIC cracks were detected after the 14 hours immersion tests on $\mathrm{X}-65$. This result correlates well with the evolution of $\mathrm{AE}$ events related to HIC. Indeed, as shown in Figure 11, HIC signals were detected after approximately 15 hours by $A E$ on $X-65$. This evolution of cracking extent with time of exposure is in good agreement with literature data ${ }^{8}$. 
Figure 12: Comparative ultrasonic C-scan of square specimens monitored by acoustic emission, after 14.5 hours (top) or 96 hours (bottom) exposure at $\mathrm{pH} 4.5$ and 1 bar $\mathrm{H}_{2} \mathrm{~S}$.

Figure 13: Evolution of CAR with time of exposure for $\mathrm{X} 65$ sweet service steel tested at $\mathrm{pH}$ 4.5 and under 1 bar $\mathrm{H}_{2} \mathrm{~S}$ (Symbols represent the average value of four replications. Upper and lower limits represent min. and max. values)..

Correlation between AE data and CAR was also investigated on a larger set of experiments, including different $\mathrm{pH}$ values (3.5 to 6.5$), \mathrm{H}_{2} \mathrm{~S}$ partial pressures ( 0.05 to 1 bar) and durations (5 to 120 hours). For each specimen monitored with $A E$, the CAR was compared to the cumulative energy $\left(E_{a b s}\right)$ of $A E$ data measured on the same specimen. This analysis was first carried out using all $\mathrm{AE}$ signals detected during the test, and then using only the AE events related to HIC, after appropriate filtering. The results are compared in Figure 14.

Figure 14: Correlation between CAR and cumulative energy of all AE events (a) and of filtered AE events related to HIC (b), measured on X65 sweet service steel tested in sour environments and for various exposure times.

When all $A E$ data are used, only a poor correlation with the extent of cracking is found. The same trend was found with other AE parameters, such as the cumulative number of "hits" or "counts". However, when AE data related to HIC are filtered according to the criterion described earlier ${ }^{9-10}$, a much better agreement is found between cumulative energy and CAR. Correlation is further improved by a second criterion. One group of data points in Figure 14 (b) shows linear dependence between $E_{a b s}$ and CAR, with a correlation coefficient $\mathrm{R}^{2}$ equal to 0.89 . The second group contains three experiments with much higher cumulative energy. After visual inspection and metallographic analysis of the specimens, the difference between both groups was discovered. All specimens of the second group which gave higher 
AE cumulative energy presented cracks open to the surface. It is believed that when these cracks reached the surface the trapped pressurised hydrogen was allowed to leak, giving rise to an excess $\mathrm{AE}$. AE events generated by the leak had similar energy and duration properties than $\mathrm{HIC}$ related $\mathrm{AE}$. For this reason, an overestimation of the cumulative energy related to HIC was obtained for these specific experiments. The corresponding experiments were then excluded from the analysis. On the other hand, for all specimens of the first group, no open cracks were observed by microscopic inspection of the lateral faces. These specimen and the corresponding $\mathrm{AE}$ and $\mathrm{CAR}$ results were then considered for further analysis. Using this group of data, a correct linear relationship between CAR and AE energy was found, showing the ability of $\mathrm{AE}$ to quantitatively monitor HIC.

\section{Application to $\mathrm{H}_{2} \mathrm{~S}$ stress cracking: SOHIC or SSC?}

For the last part of this paper, the methodology was applied to evaluate the behavior of two sour service steels (sour service X65 and C110) under an applied load corresponding to 90\%AYS. The experiments were carried out at $\mathrm{pH} 3.5$ and 1 bar $\mathrm{H}_{2} \mathrm{~S}$. For these two steels preliminary experiments carried out without applied load on conventional HIC specimens and on specimens equipped with $A E$ monitoring confirmed that both steels were not susceptible to $\mathrm{HIC}$ under the same $\mathrm{pH}$ and $\mathrm{H}_{2} \mathrm{~S}$ exposure. AE results obtained at $90 \% \mathrm{AYS}$ applied load are presented in Figure 15 and Figure 16. For both kinds of test, the specimens failed within less than 150 hours.

Figure 15: AE data obtained during exposure tests at $\mathrm{pH} 3.5$ and 1 bar $\mathrm{H}_{2} \mathrm{~S}$ for sour service X65 steel with $90 \%$ YS applied load (time to failure 36 hours).

Figure 16: $\mathrm{AE}$ data obtained during exposure tests at $\mathrm{pH} 3.5$ and 1 bar $\mathrm{H}_{2} \mathrm{~S}$ for $\mathrm{C} 110$ steel with $90 \%$ YS applied load (time to failure 132 hours). 
Compared to the $\mathrm{AE}$ correlation chart showing the $\mathrm{HIC}$ region (Figure 2), the results obtained on $\mathrm{X} 65$ steel contained $\mathrm{AE}$ signals representative of $\mathrm{HIC}$, while the tests conducted on the C110 grade did not. These results clearly indicate that the failure mechanism is not identical for both types of steels. Furthermore, the presence of HIC signals for the tests on the X65 steel (that were not detected during tests without applied load) suggested a SOHIC mode of failure, while the absence of HIC signals for the C110 was more in favour of a SSC type of fracture. These assumptions were verified by SEM observation.

On the X65 fracture surface (Figure 17) several internal cracks with a HIC appearance were identified. Ductile microvoids could also be observed at higher magnification. Furthermore, the rupture was oriented at $45^{\circ}$ of the applied stress, typical of ductile fracture. From these observations, the fracture of sour service X65 sample is not consistent with a SSC mechanism. The plastic deformation and the presence of internal cracks perpendicular to the fracture surface on one hand and the detection of HIC signals by AE on the other, strongly suggest a SOHIC mode of failure.

The fracture surface of the $\mathrm{C} 110$ steel is quite different (Figure 18). Two areas with different aspect and orientation were identified. The first area had a circular shape, and was oriented perpendicular to the surface of the specimen and to the applied load. Higher magnification observation indicated a brittle-like fracture, with transgranular decohesion. The other part of the fracture was orientated at $45^{\circ}$ of the applied load, and was ductile. This profile, with a brittle-like flat surface perpendicular to the direction of applied load and a second $45^{\circ}$ ductile region, is typical of SSC induced failure. In that case, SSC corresponds to the brittle area. Then, as the section of the loaded part is reduced, the applied stress reaches the UTS and the sample fails at $45^{\circ}$ by ductile fracture.

Figure 17: Fracture surface of $\mathrm{X} 65$ sour service steel after testing at $\mathrm{pH} 4.5$ and 1 bar $\mathrm{H}_{2} \mathrm{~S}$, with $90 \%$ YS applied load. Low (a) and high (b) magnification. 
Figure 18: Fracture surface of $\mathrm{X} 65$ sour service steel after testing at $\mathrm{pH} 4.5$ and 1 bar $\mathrm{H}_{2} \mathrm{~S}$, with $90 \%$ YS applied load. Low magnification (a) and high magnification observation of the circular brittle area (b) and of the $45^{\circ}$ ductile area (c).

From these experiments under applied load, AE proved its ability to discriminate between different types of cracking. Furthermore, it gave clear indications that SOHIC is closely related to HIC, which is well agreed in the literature, but also that SSC proceeds by a completely different mechanism. On the contrary to the brittle decohesion step of HIC, which gave rise to high energy and high duration AE events, the initial brittle fracture of SSC does not present significant $A E$ activity. A hypothesis to explain these differences could lie on the crack growth rate. In the case of SSC, crack is thought to proceed extremely slowly ${ }^{30-32}$, while for HIC, brittle decohesion is more sudden. This is also in good agreement with the EA results, since it is known that faster events give $A E$ with higher energy ${ }^{33-34}$.

\section{CONCLUSIONS}

AE methodology previously developed by the authors was used to monitor HIC and obtain a better understanding of the HIC process.

Correlation of the cumulative energy of filtered $A E$ events and crack area nature of three steels of increasing strength was consistent with the following narrative:

1. Immediately after exposure, hydrogen diffuses in the steel and accumulates at weak interfaces. At this stage, no cracking occurs and no AE related to HIC is measured. The duration of this incubation period depends on several factors, like permeation rate, size of the specimen, location of hydrogen traps, etc.

2. At the end of this initial period, when the critical hydrogen level at trap sites is reached, decohesion of weak interfaces is likely to occur. This corresponds to the very first stage of cracking, and is probably of brittle nature. AE events corresponding 
to this brittle fracture present a sharp rise, with an energy level correlated to the size of the crack.

3. Once an initial crack is present in the steel, gaseous hydrogen accumulates in the blister volume until the pressure becomes sufficient to propagate the crack. This propagation is probably ductile. The related EA continuously increases.

4. After a period of time, crack propagation decreases and eventually ceases.

It was shown also that quantitative evaluation of $\mathrm{HIC}$ could be obtained after AE signal discrimination. AE also proved its ability to detect different cracking mechanisms, and to distinguish between SOHIC and SSC. Further experiments are carried out using the same AE analysis to study specifically SSC mechanisms. The results are intended for further publication.

The results of this work also have some Implications for the oil and gas industry and for sour service qualification methods of steels. $\mathrm{AE}$ analysis confirmed that the onset of internal cracking appeared after several hours of immersion. This could be related to the time required to reach a sufficient hydrogen activity within the steel.

It was shown also that the duration of the propagation phase depended on the steel type. One governing factor seems to be related to the location and thickness of the segregation area. For steel with microstructural defects located in a thin zone at the centre line, cracking is very sudden and affects a large area. For steels with a broader distributed segregation, cracking is more progressive and proceeds by ductile fractures between adjacent small cracks. The second type of steels might present safer use in the field, leaving some time to detect cracks before they reach their maximum extension.

From this work, the impact of applied load on internal cracking was not fully elucidated. Nevertheless, it appears clearly that SOHIC proceeds by the same mechanism than HIC. The direct consequence is that testing steels for SOHIC should be made though standard tests of the same duration than HIC. 
As a perspective, experiments in less severe environments and with a broader range of steel types are necessary to confirm these preliminary conclusions, and to gain acceptance by the industry. Complementary use of hydrogen permeation should be of great value to reach quantitative correlations between typical cracking times and hydrogen diffusion processes.

\section{ACKNOWLEDGMENTS}

The authors would like to thank M. Boinet (Euro-Physical Acoustics), for his help in the analysis of $A E$ data, and L. Garnier and G. Parrain, who carried out most of the HIC experiments. H. Marchebois (Vallourec) and J.L. Crolet are also acknowledged for helpful discussions on $\mathrm{H}_{2} \mathrm{~S}$ cracking mechanisms.

\section{REFERENCES}

[1] NACE MR0175/ISO 15156-1, Petroleum and natural gas industries - Materials for use in $\mathrm{H}_{2} \mathrm{~S}$ containing environments in oil and gas production - Part 1: General principles for selection of cracking-resistant materials (2001).

[2] NACE MR0175/ISO 15156-2, Petroleum and natural gas industries - Materials for use in $\mathrm{H}_{2} \mathrm{~S}$ containing environments in oil and gas production - Part 2: Cracking-resistant carbon and low alloy steel, and the use of cast iron (2003).

[3] EFC publication $n^{\circ} 16$, Guidelines on materials requirements for carbon and low alloy steels for $\mathrm{H}_{2} \mathrm{~S}$-containing environments in Oil and Gas production, The Institute of Materials, London, UK, 1995.

[4] NACE TM0284-2003, Evaluation of pipeline and pressure vessel steels for resistance to hydrogen-induced cracking, NACE International, Houston Texas, 2003. 
[5] NACE TM0177-96, Laboratory testing of metals for resistance to specific forms of environmental cracking in $\mathrm{H}_{2} \mathrm{~S}$ environments, NACE International, Houston Texas, 1996.

[6] NACE TM0103-2003, Laboratory test procedures for evaluation of SOHIC resistance of plate steels used in wet $\mathrm{H}_{2} \mathrm{~S}$ service, NACE International, Houston Texas, 2003.

[7] J. Kittel, J.W. Martin, T. Cassagne, C. Bosch, "Hydrogen induced cracking (HIC) Laboratory testing assessment of low alloy steel linepipe," Corrosion/2008, paper no. 110 (Houston, TX:NACE, 2008).

[8] J. Kittel, V. Smanio, M. Fregonese, L. Garnier, X. Lefebvre, Corrosion Science 52, (2010): p. 1386.

[9] V. Smanio, M. Fregonese, J. Kittel, T. Cassagne, F. Ropital, B. Normand, Journal of Materials Science 45 (2010): p. 5534.

[10] . V. Smanio, T. Cassagne, F. Ropital, J. Kittel, M. Fregonese, B. Normand, "Evaluation of hydrogen embrittlement induced damages in steels using acoustic emission", Corrosion/2008, paper no. 111 (Houston, TX:NACE, 2008).

[11] H. Mazille, R. Rothéa, "The use of acoustic emission for the study and monitoring of localized corrosion phenomena", Tretheway KR, Roberge PR, editors. Modelling aqueous corrosion, Netherlands: Kluwer Academic (1994): p. 103.

[12] W.J. Pollock, D. Hardie, N.J.H. Holroyd, British Corrosion Journal 17, 3 (1982): p. 103.

[13] W.W. Gerberich, R.H. Jones, M.A. Friesel, N. Nozue, Materials Science and Engineering 103 (1988): p. 185.

[14] F. Ferrer, H. Idrissi, H. Mazille, P. Fleischmann, P. Labeeuw, Wear 231 (1999): p. 108.

[15] R.H. Jones, M.A. Friesel, Corrosion 48, 9 (1992): p. 751.

[16] H. Mazille, R. Rothea, C. Tronel, Corrosion Science 37, 9 (1995): p. 1365.

[17] M. Fregonese, H. Idrissi, H. Mazille, L. Renaud, Y. Cetre, Journal of Materials Science 36 (2001): p. 557.

[18] Y.P. Kim, M. Fregonese, H. Mazille, D. Féron, G. Santarini, NDT\&E International 36 (2003): p. 553. 
[19] Y.P. Kim, M. Fregonese, H. Mazille, D. Féron, G. Santarini, Corrosion Science 48, 12 (2006): p. 3945.

[20] F. Bellanger, H. Mazille, H. Idrissi, NDT\&E International 35 (2002): p. 385.

[21] L. Jaubert, M. Fregonese, D. Caron, F. Ferrer, C. Franck, E. Gravy, P. Labeeuw, H. Mazille, L. Renaud, Insight 47, 8 (2005): p. 465.

[22] S. Yuyama, T. Kishi, Y. Hisamatsu, Journal of Acoustic Emission, vol.2 n¹/2, 71-93 (1983).

[23] C.C. Weng, R.T. Chen, Journal of Chinese Institute of Engineers 16, 4 (1993): p. 489.

[24] C.C. Weng, R.T. Chen, Journal of the Chinese Institute of Engineers 16, 2 (1993): p. 195.

[25] M.S. Cayard, R.D. Kane, "Evaluation of various methods of reducing the duration of SSC qualification testing", Corrosion/97, paper no. 57 (Houston, TX:NACE, 1997).

[26] S.Y. Tsai, H.C. Shih, Journal of the Electrochemical Society 145, 6 (1988): p. 1968.

[27] A.D.B. Gingell, X.Garat, "Observations of damage modes as a function of microstructure during NACE TM0177-96 tensile testing of API 5L grade X60 linepipe steel", Corrosion/99, paper no. 600 (Houston, TX:NACE, 1999).

[28] S. Amami, P. Marchand, S. Duval, X. Longaygue, M. Fregonese, H. Mazille, J.P. Millet, "Detection by acoustic emission technique of the corrosion stress cracking within steel structures in $\mathrm{H}_{2} \mathrm{~S}$ containing mediums", Eurocorr 2003, The European Federation of Corrosion (2003).

[29] J.L. Crolet, M.R. Bonis, "Revisiting hydrogen in steel, part I: theoretical aspects of charging, stress cracking and permeation", Corrosion/2001, paper no. 67 (Houston, TX:NACE, 2001).

[30] H.A. Ernst, J. Villasante, N. Pachao, D. Johnson, "Specimen geometry effects on crack growth in sour environment", Corrosion/2002, paper no. 60 (Houston, TX:NACE, 2002).

[31] K.E. Szklarz, "Understanding the size effect in NACE TM0177 method D (DCB) testing and implication for users", Corrosion/2001, paper no. 74 (Houston, TX:NACE, 2001).

[32] J.L. Albarran, L. Martinez, H.F. Lopez, Corrosion Science 41, 6 (1999): p. 1037. 
[33] D.G. Eitzen, H.N.G. Wadley, Journal of Research of the National Bureau of Standards 89, 1 (1984): p. 75.

[34] H.L. Dunegan, A.T. Green, Materials Research and Standard 11, 3 (1971): p. 21. 
Table 1: Chemical composition (wt \%) of tested steels (bal. Fe).

\begin{tabular}{|c|c|c|c|c|c|c|c|c|c|c|}
\hline & $\mathbf{C}$ & Mn & Si & P & S & Cr & Ni & Mo & Cu & Nb \\
\hline sweet grades \\
\hline X60 & 0.098 & 1.40 & 0.238 & 0.017 & 0.006 & 0.046 & 0.046 & 0.009 & 0.077 & 0.025 \\
\hline X65 & 0.09 & 1.56 & 0.28 & 0.014 & 0.001 & 0.05 & 0.03 & 0.01 & 0.02 & 0.040 \\
\hline X70 & 0.12 & 1.26 & 0.274 & 0.001 & 0.003 & 0.042 & 0.044 & 0.01 & 0.055 & 0.035 \\
\hline \\
sour grades \\
\hline X65 SS & 0.046 & 1.36 & 0.322 & 0.008 & 0.001 & 0.041 & 0.036 & 0.008 & 0.047 & 0.045 \\
\hline C110 & 0.309 & 0.394 & 0.343 & 0.015 & 0.002 & 0.964 & 0.037 & 0.834 & 0.018 & 0.033 \\
\hline
\end{tabular}




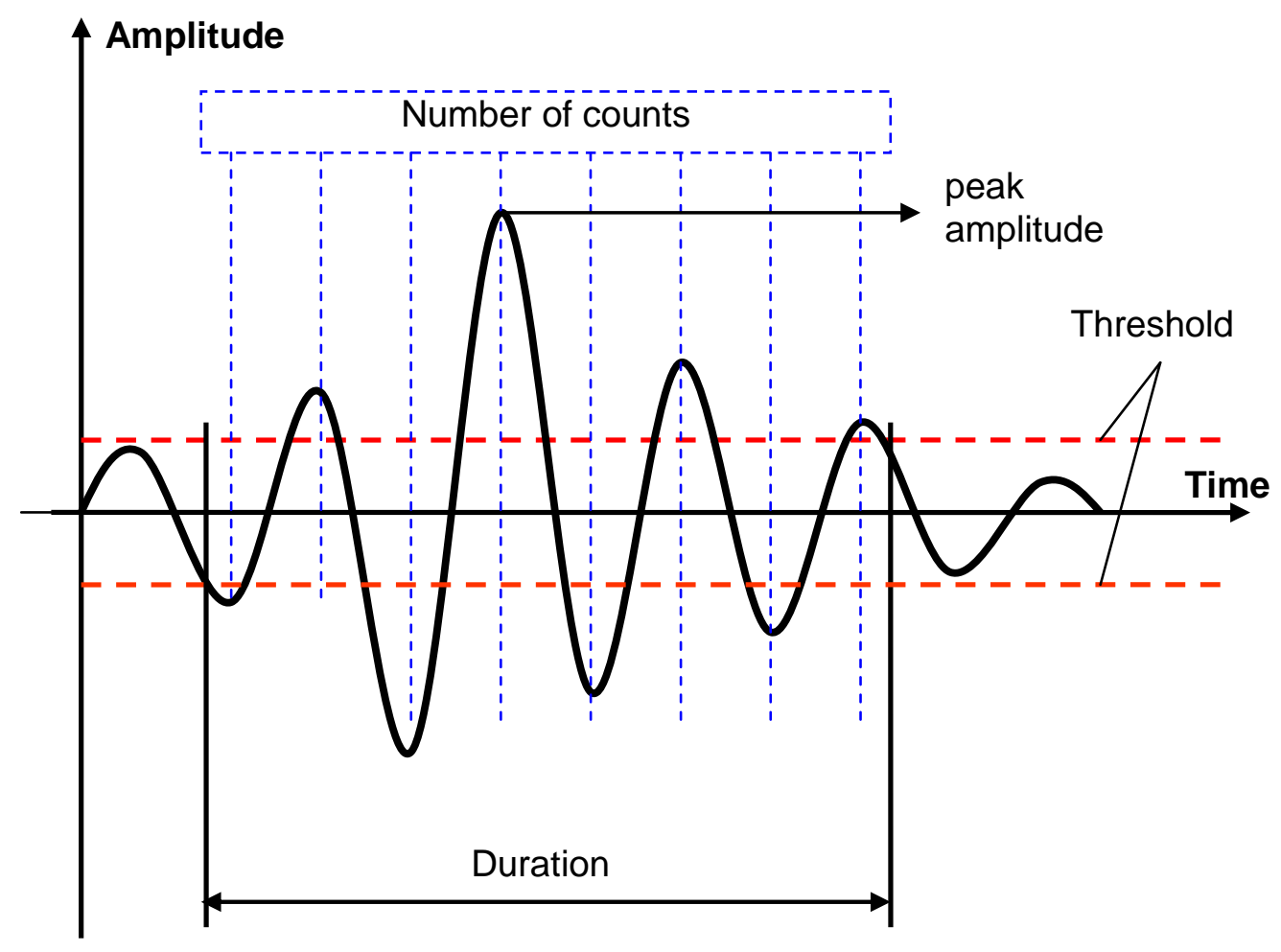

Figure 1: Typical AE waveform and characteristic parameters. 


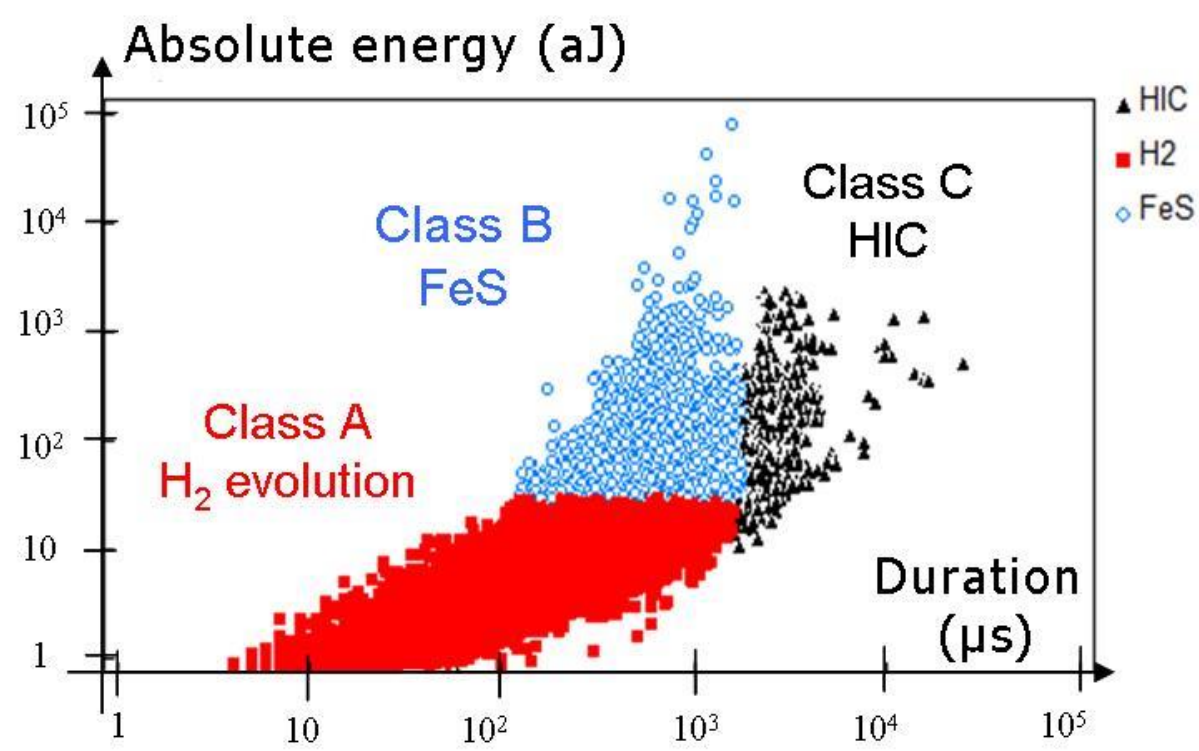

Figure 2: Representation of AE events in absolute energy as a function of signal duration, used to link each $A E$ event to its physical source (experimental data from exposure test on X65 sweet service steel in EFC16 test solution at pH 4.5 and under 1 bar H2S)9. 


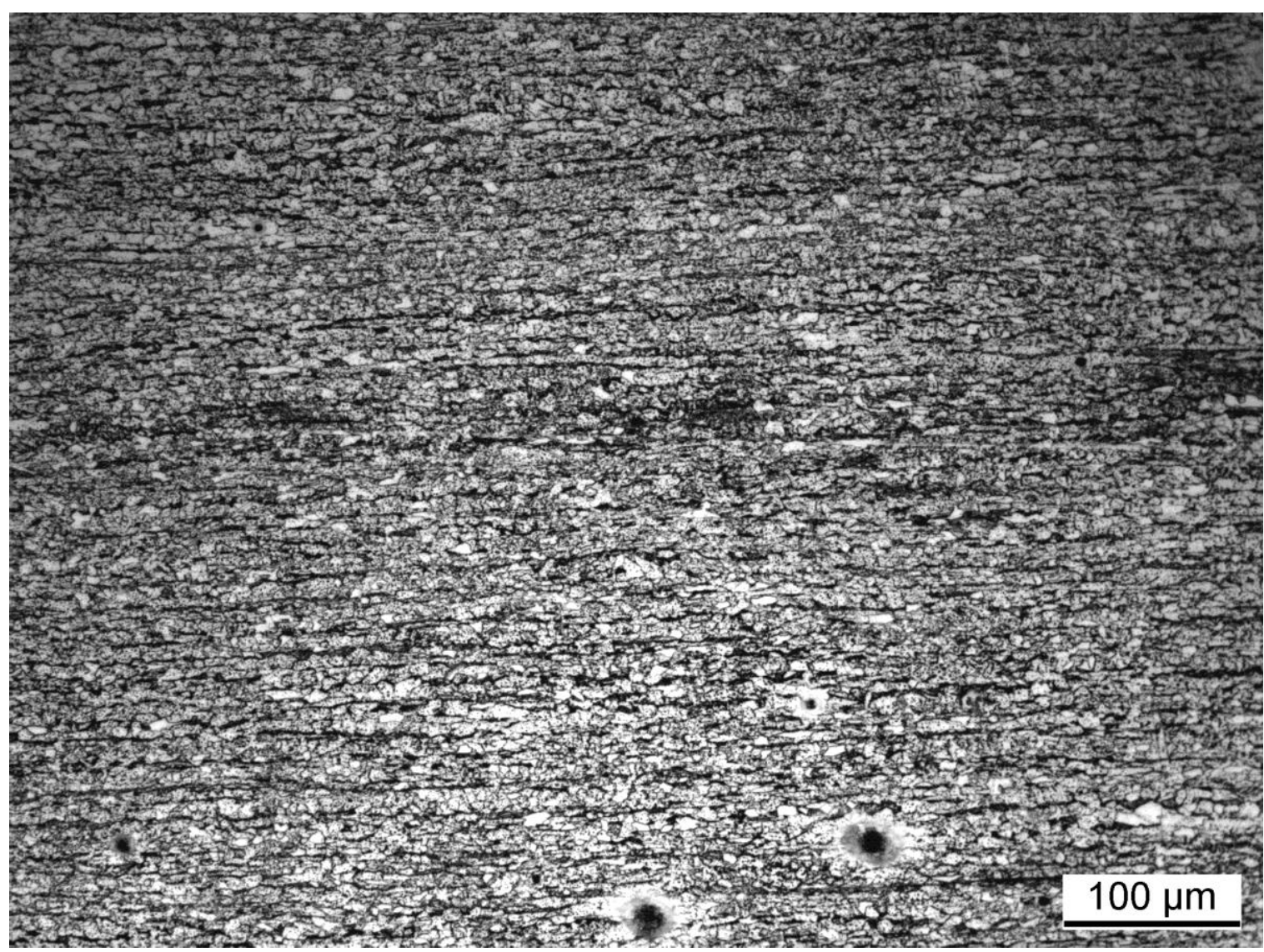

Rolling direction

Figure 3: Microstructure of the X60 sweet service grade (LT plane) 


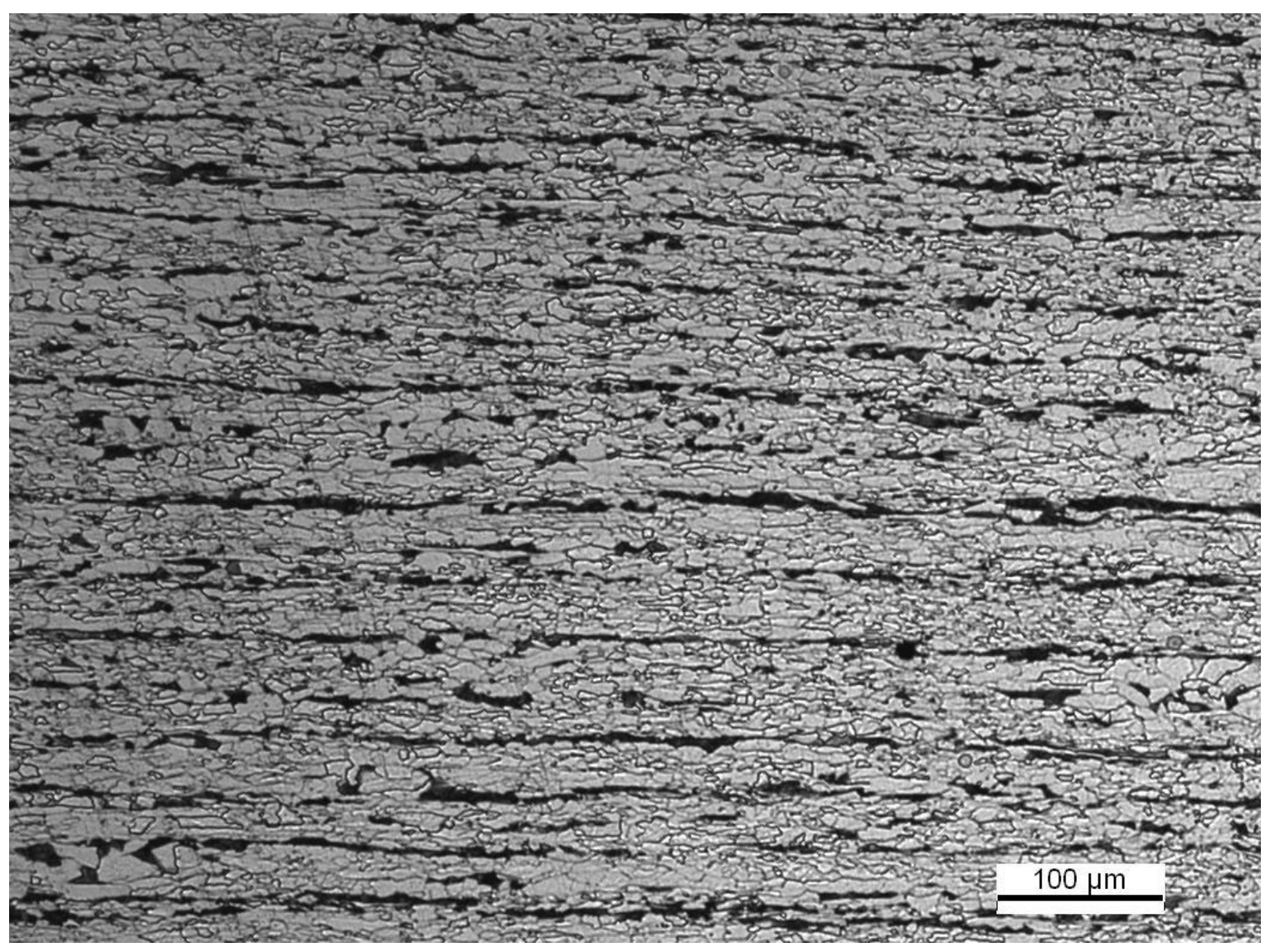

Rolling direction

Figure 4: Microstructure of the X65 sweet service grade (LT plane) 


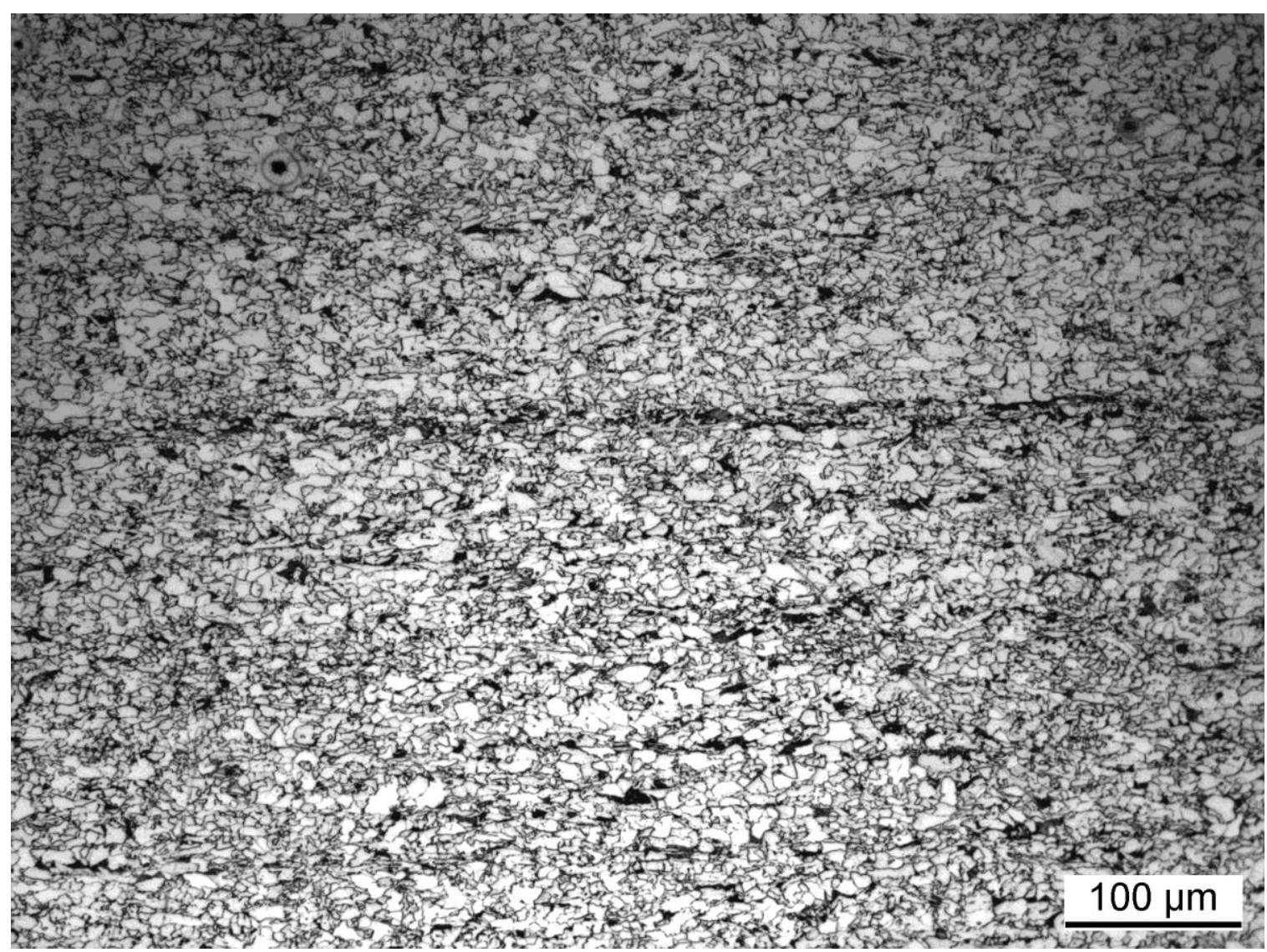

Rolling direction

Figure 5: Microstructure of the X70 sweet service grade (LT plane) 


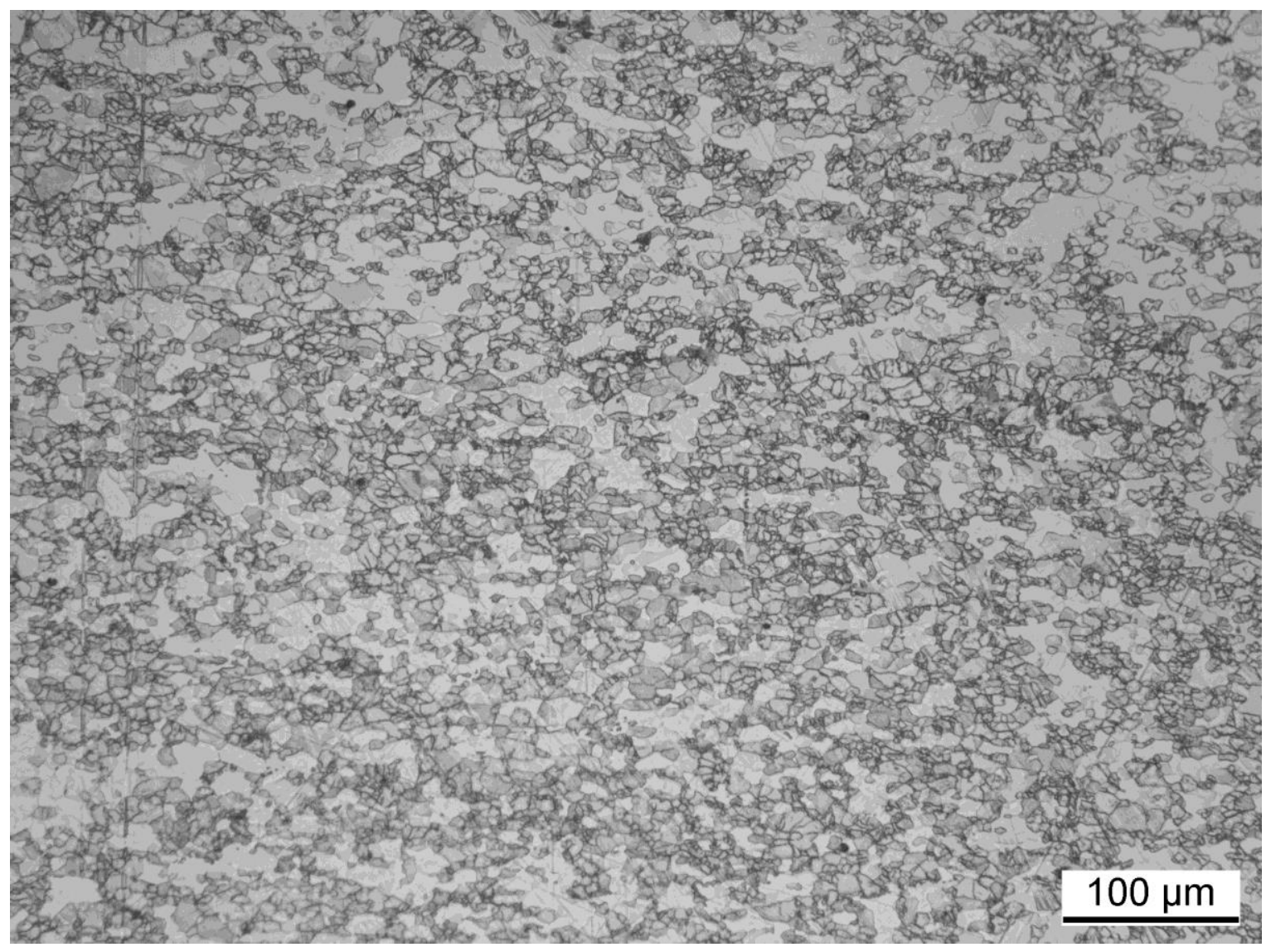

Rolling direction

Figure 6: Microstructure of the X65 sour service grade (LT plane) 


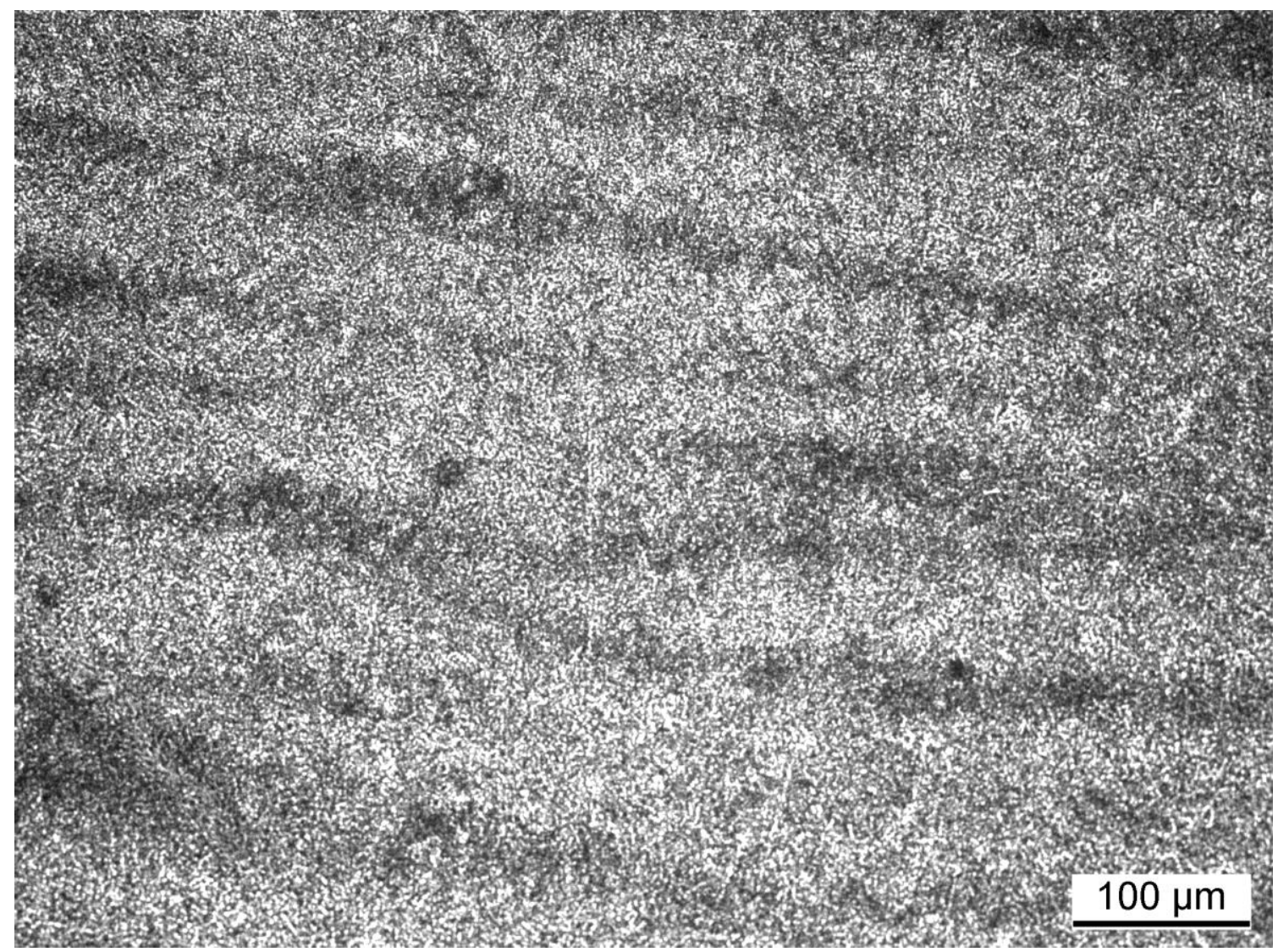

Rolling direction

Figure 7: Microstructure of the C110 sour service grade (LT plane) 


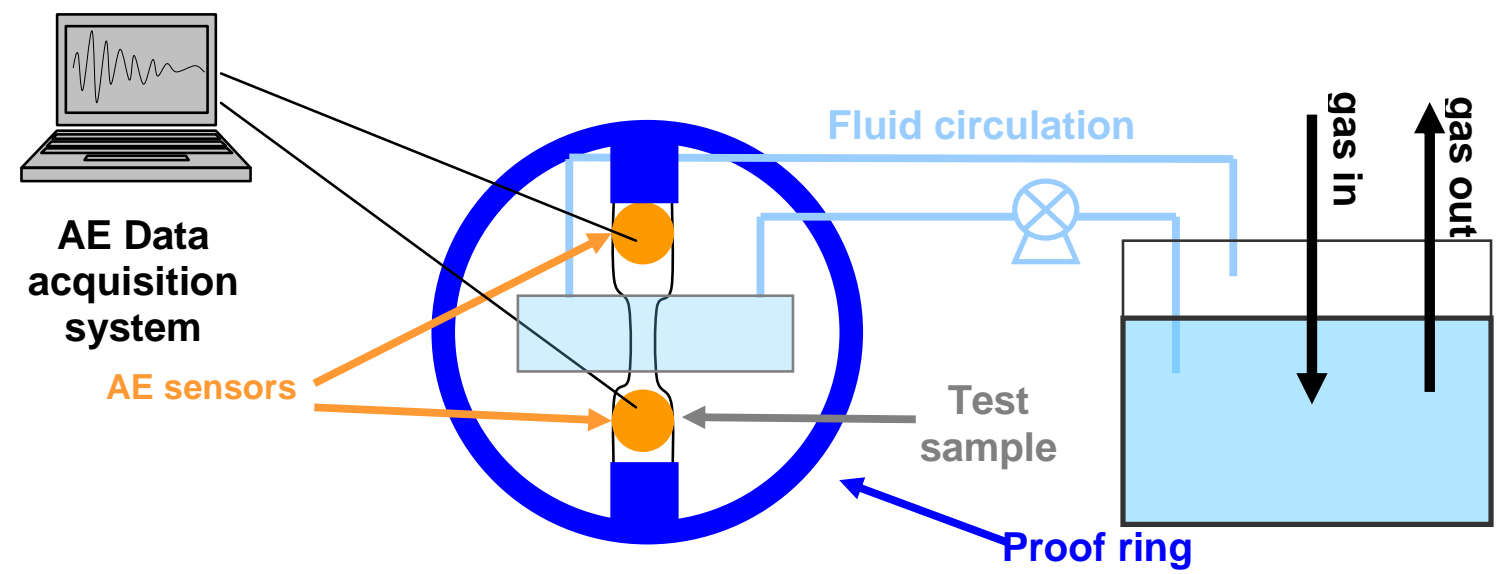

Figure 8: Experimental set-up for AE monitoring of H2S exposure tests, with or without applied load. 


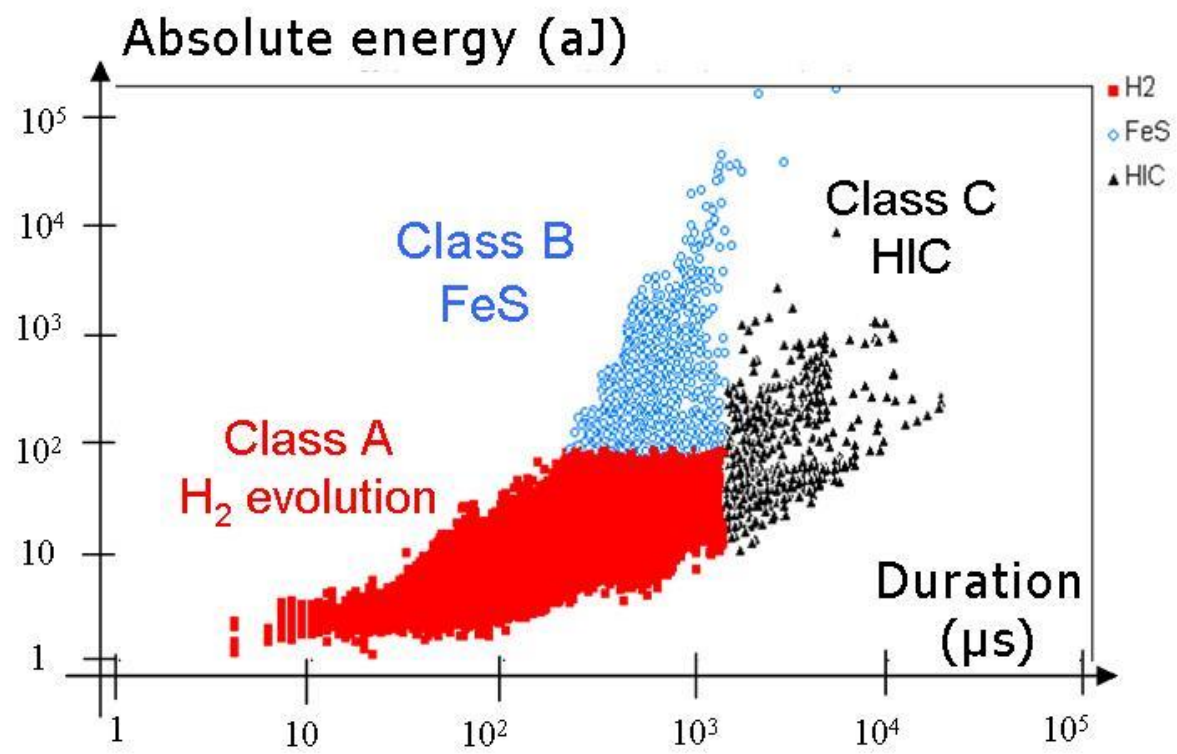

a) $X 60$

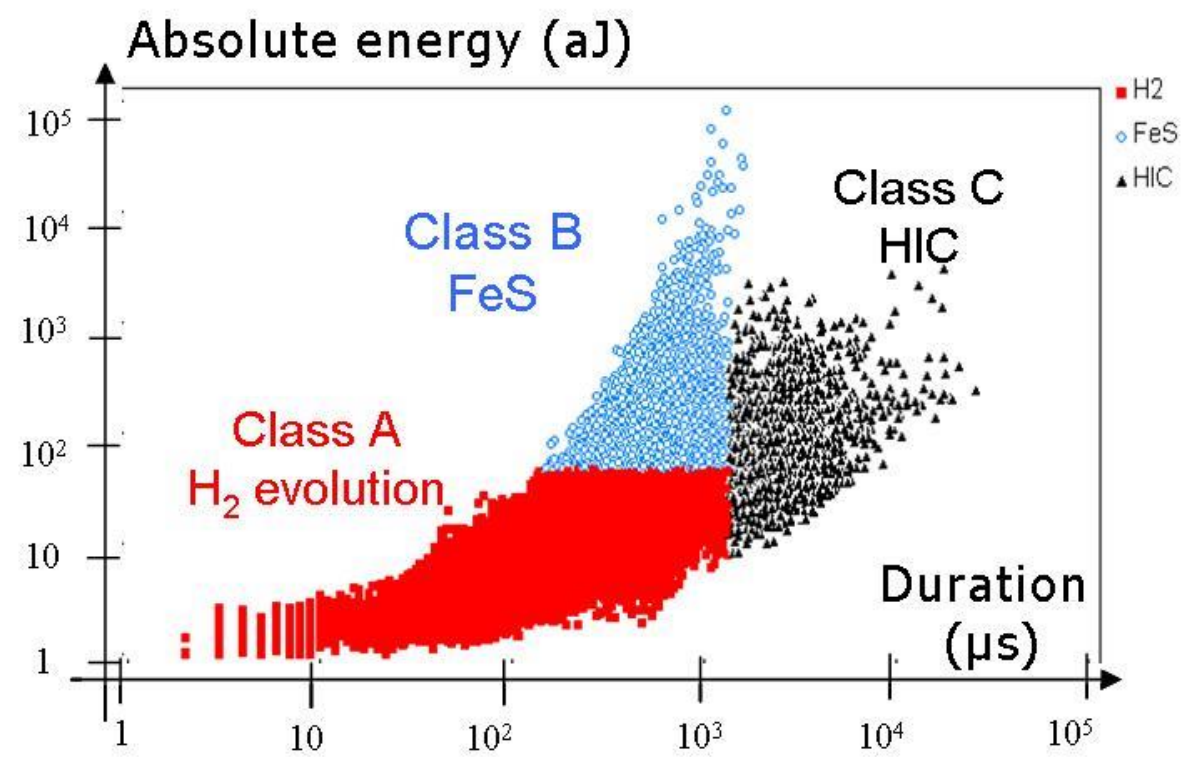

b) $X 65$ 


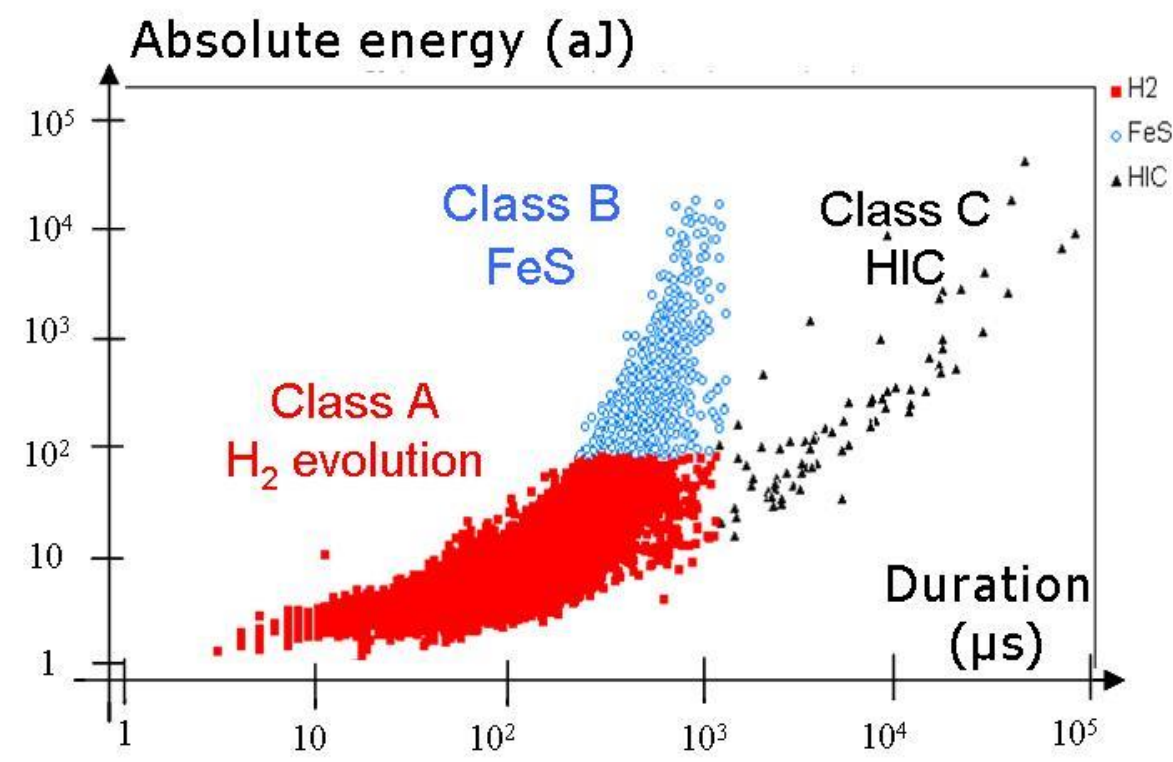

c) $X 70$

Figure 9: AE data obtained during 96 hours exposure tests at $\mathrm{pH} 4.5$ and under 1 bar $\mathrm{H} 2 \mathrm{~S}$ for three different sweet service steels $(X 60, X 65, X 70)$. Separation of $A E$ data related to HIC. 


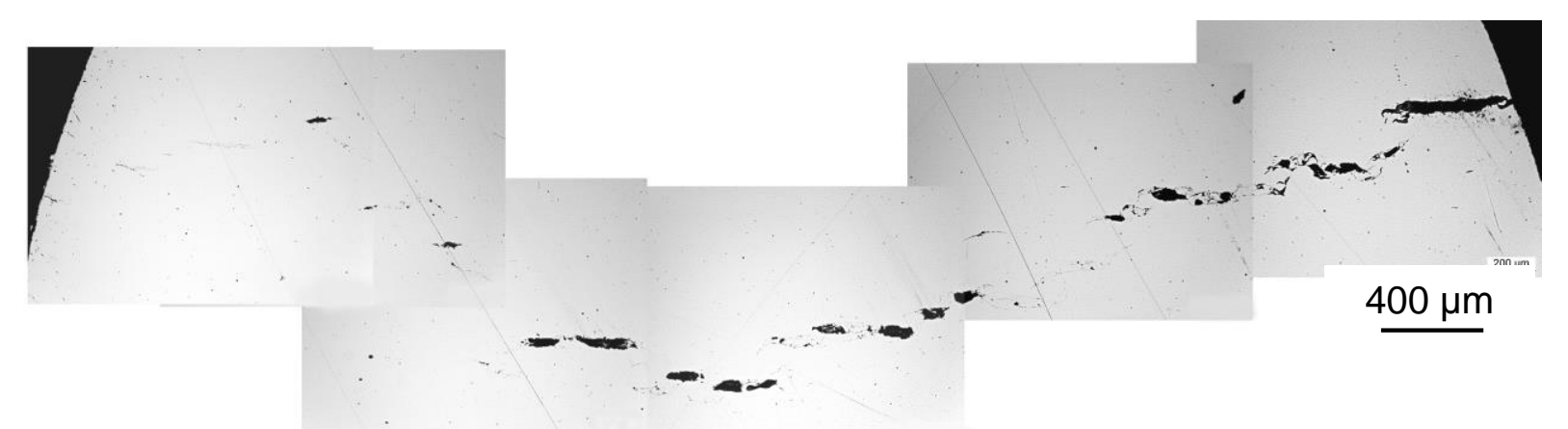

a) $\times 60$

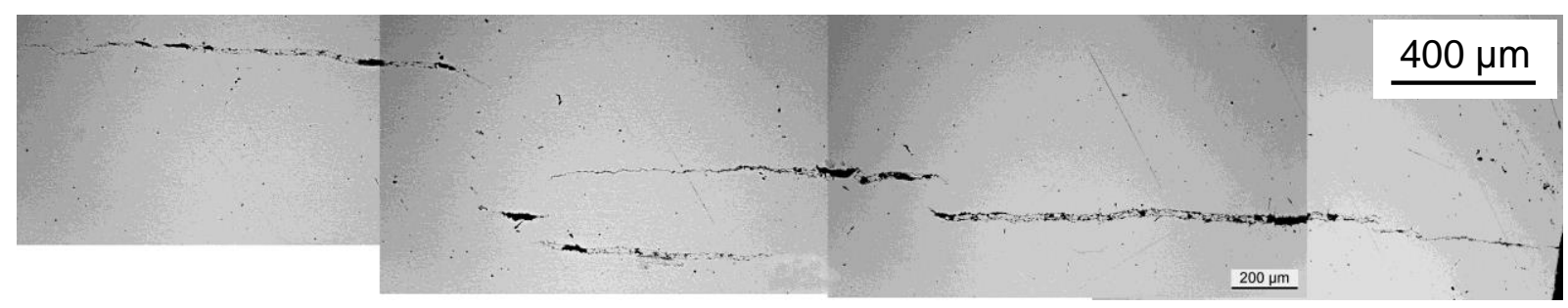

b) $\times 65$

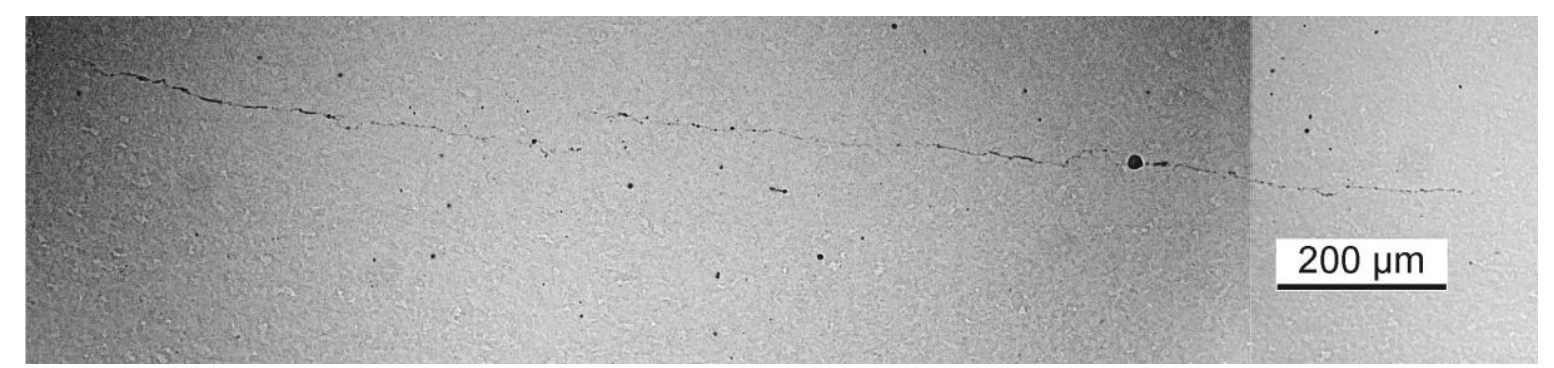

c) $\times 70$

Figure 10: Aspect of HIC cracks for different sweet service steels (X60, X65, X70) after 96 hours exposure at $\mathrm{pH} 4.5$ under 1 bar $\mathrm{H} 2 \mathrm{~S}$. 


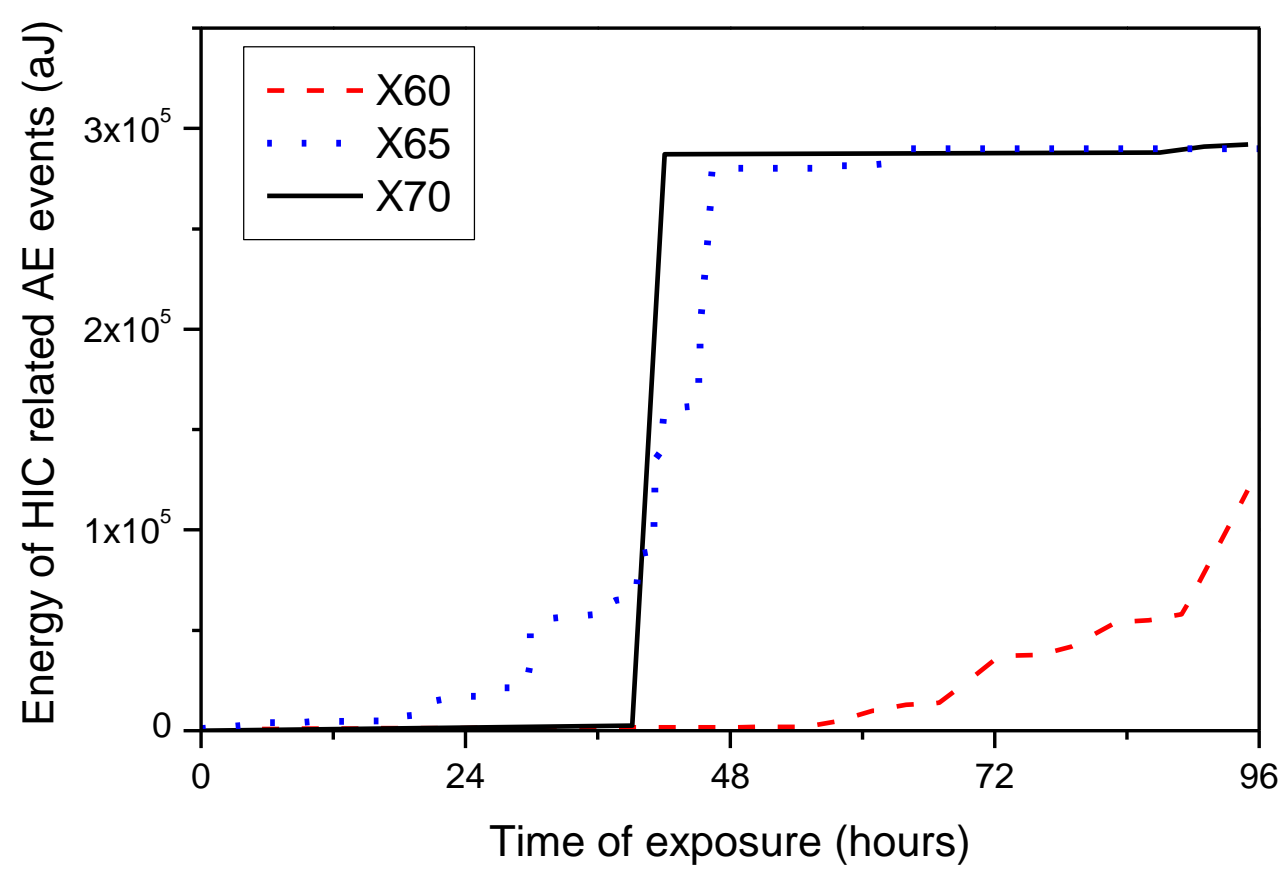

Figure 11 : Comparative evolution of cumulative energy of AE events related to HIC for tests on different sweet service steels (X60, X65 and X70) at pH 4.5 and under 1 bar H2S. 


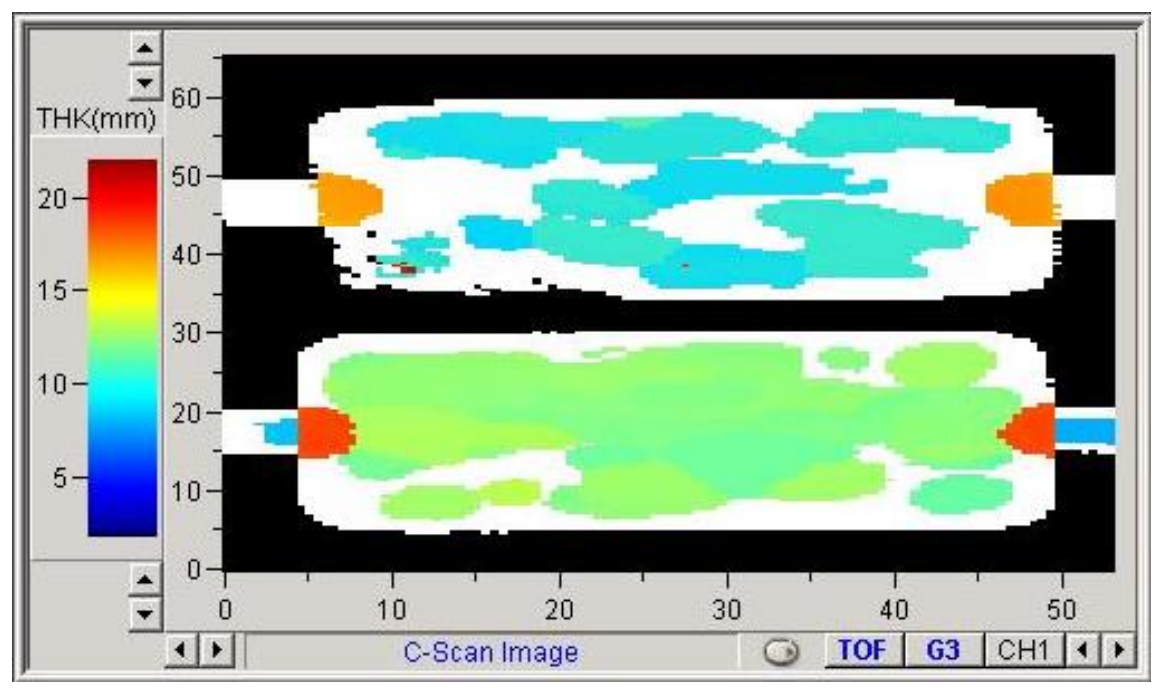

Figure 12: Comparative ultrasonic C-scan of square specimens monitored by acoustic emission, after 14.5 hours (top) or 96 hours (bottom) exposure at pH 4.5 and 1 bar H2S. 


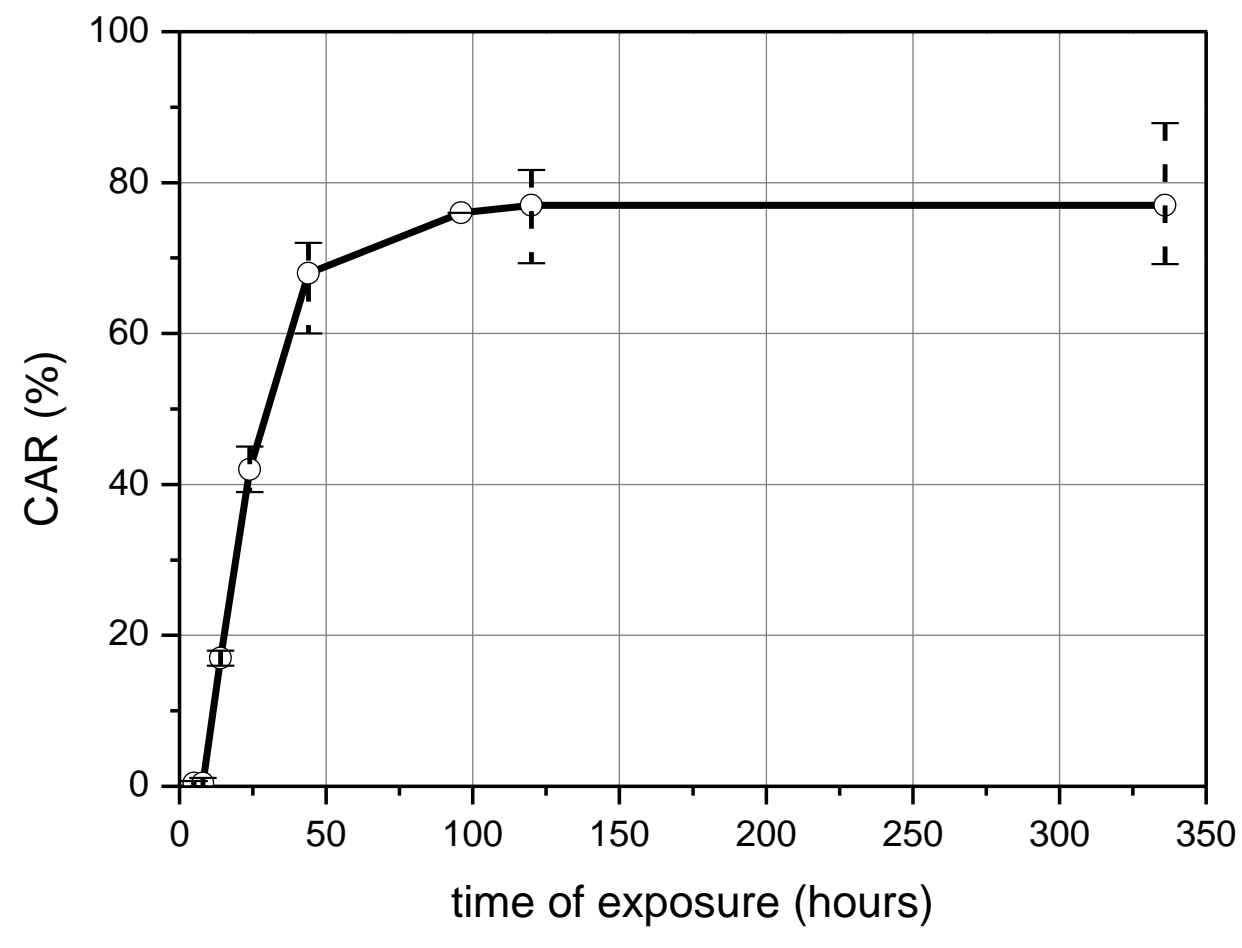

Figure 13: Evolution of CAR with time of exposure for $\mathrm{X} 65$ sweet service steel tested at $\mathrm{pH}$ 4.5 and under 1 bar H2S (Symbols represent the average value of four replications. Upper and lower limits represent min. and max. values). 


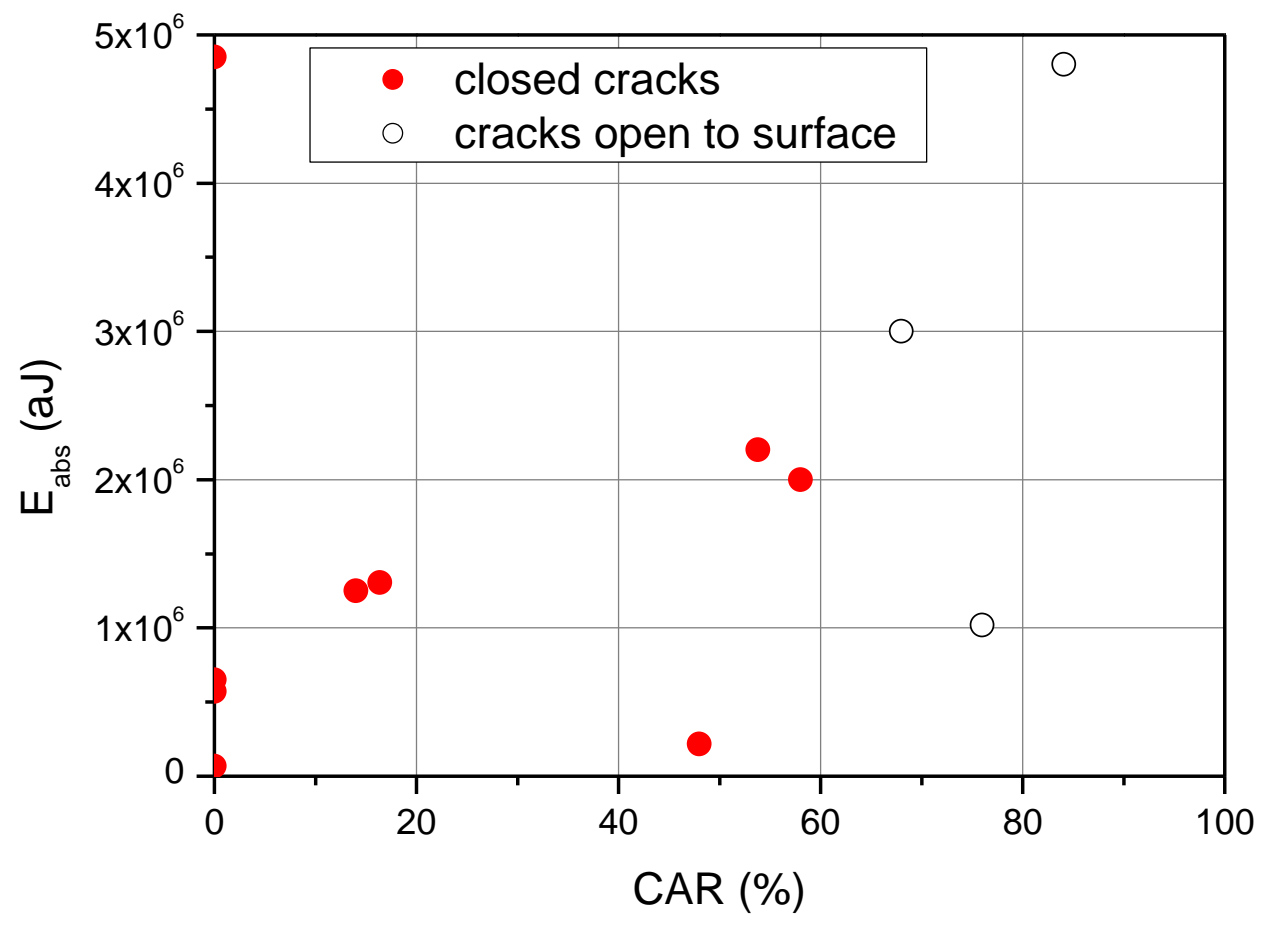

(a)

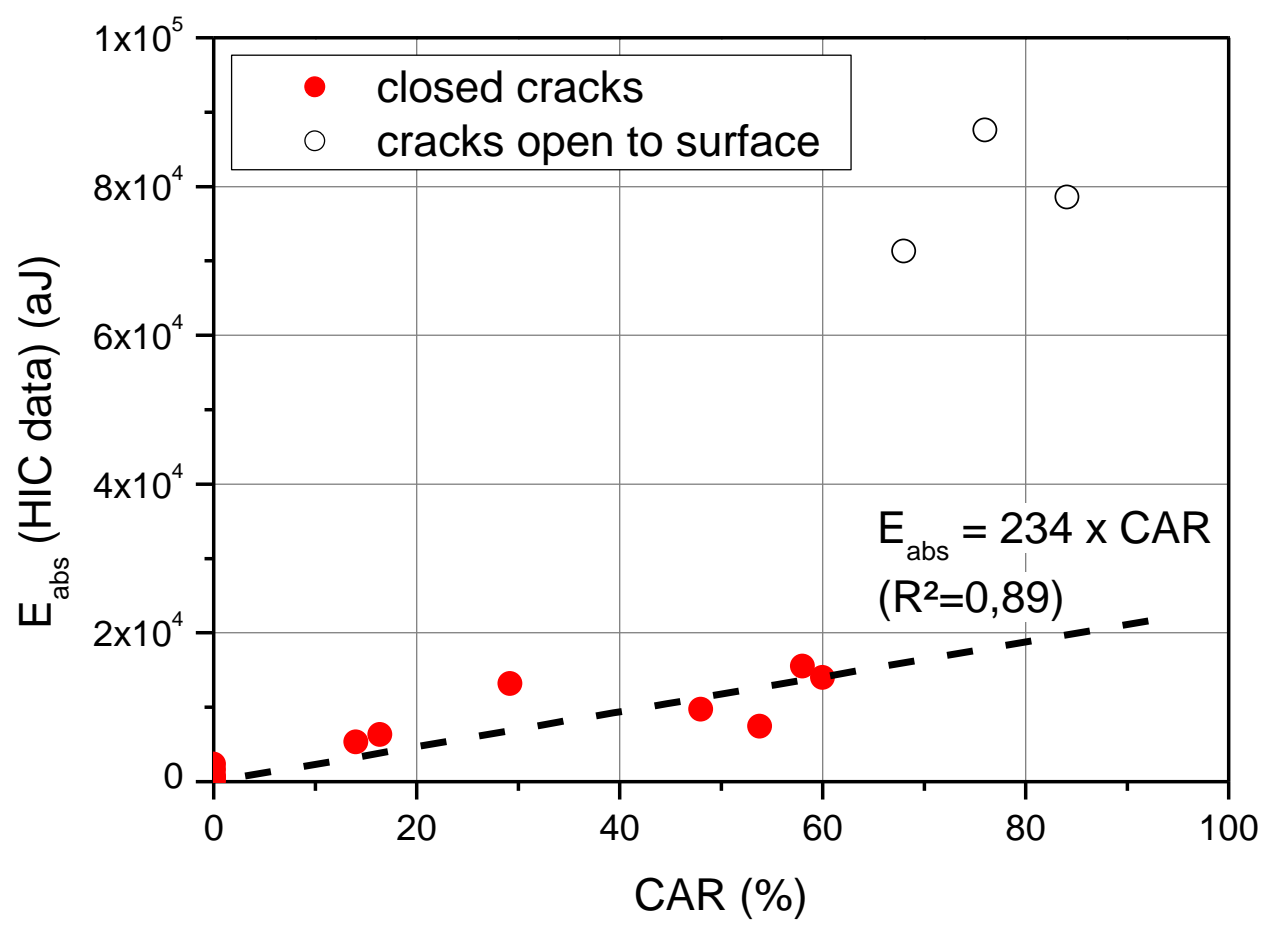

(b)

Figure 14: Correlation between CAR and cumulative absolute energy of all AE events (a) and of filtered $\mathrm{AE}$ events related to $\mathrm{HIC}(\mathrm{b})$, measured on $\mathrm{X} 65$ sweet service steel tested in sour environments and for various exposure times. 


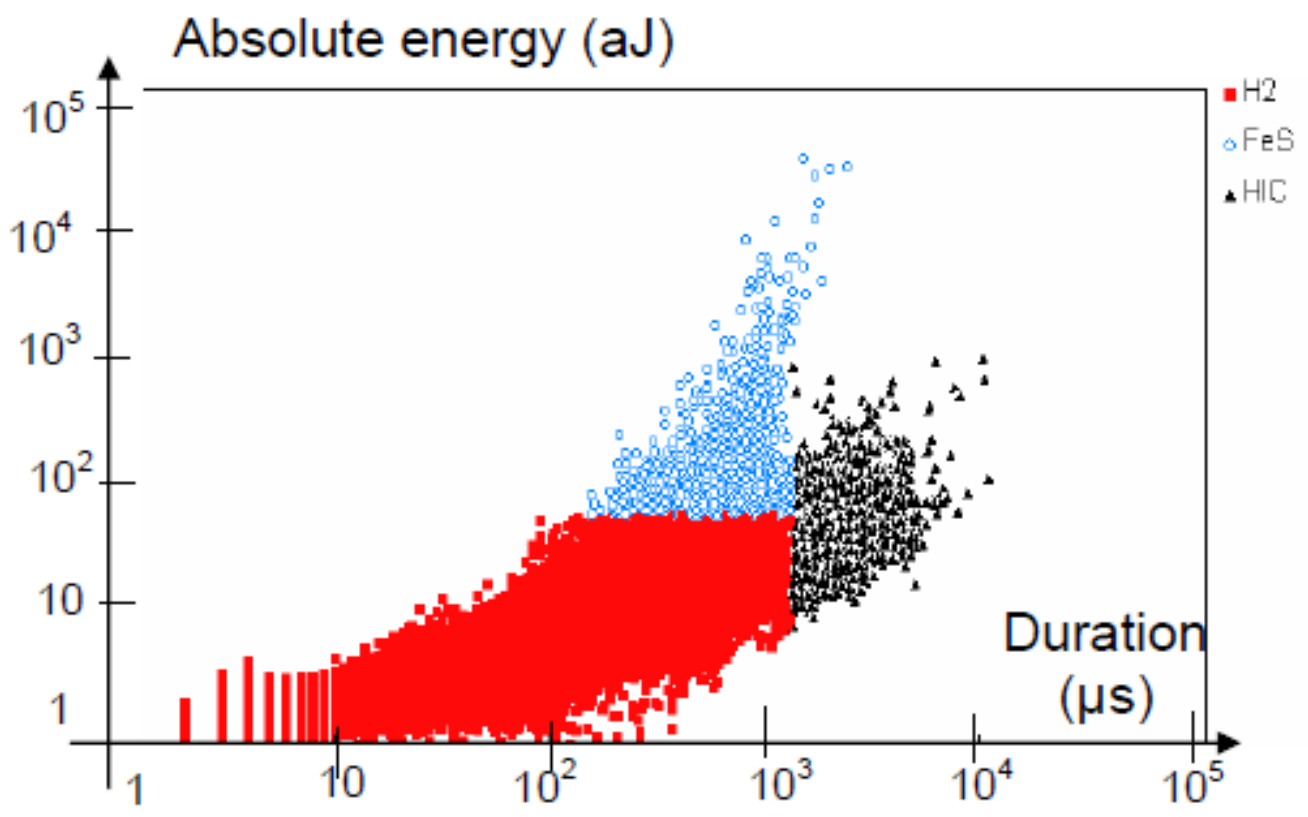

Figure 15: AE data obtained during exposure tests at $\mathrm{pH} 3.5$ and 1 bar $\mathrm{H} 2 \mathrm{~S}$ for sour service X65 steel with $90 \%$ YS applied load (time to failure 36 hours). 


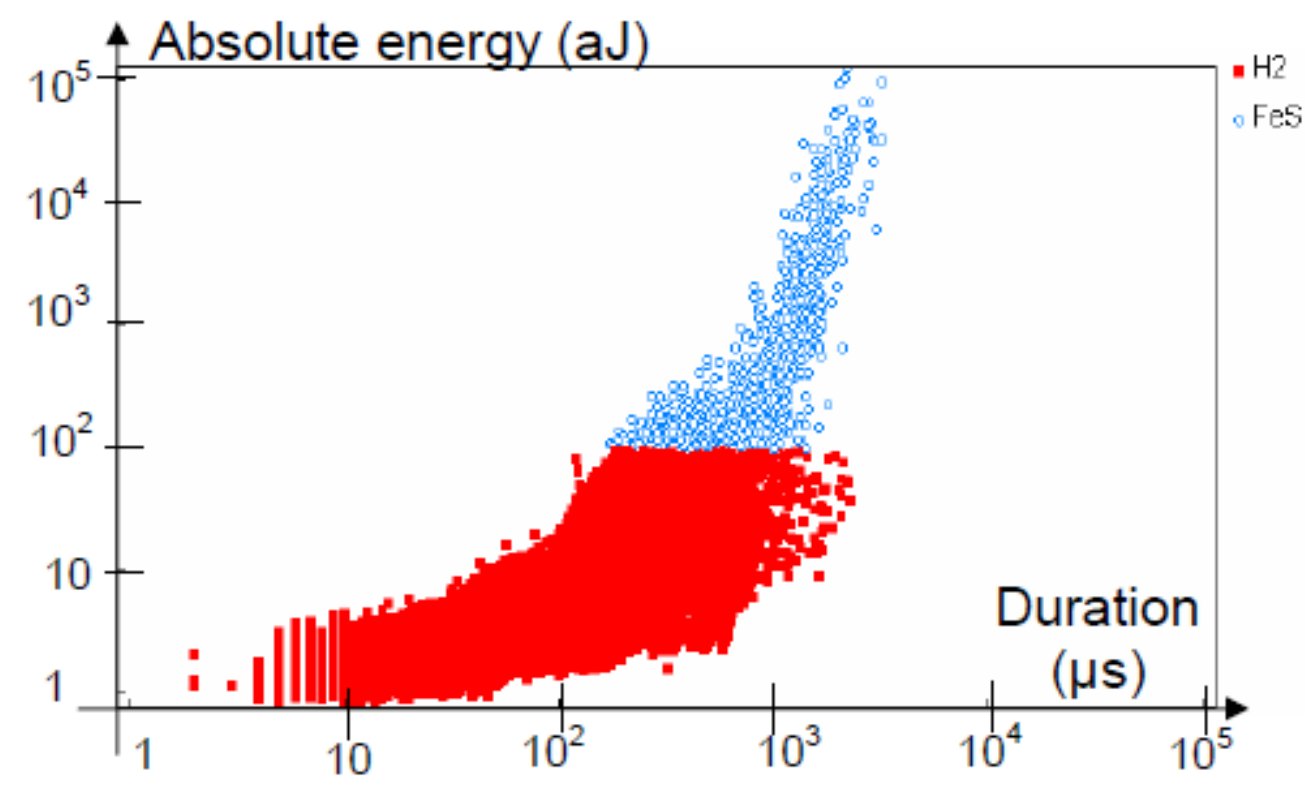

Figure 16: $\mathrm{AE}$ data obtained during exposure tests at $\mathrm{pH} 3.5$ and 1 bar $\mathrm{H} 2 \mathrm{~S}$ for $\mathrm{C} 110$ steel with $90 \%$ YS applied load (time to failure 132 hours). 


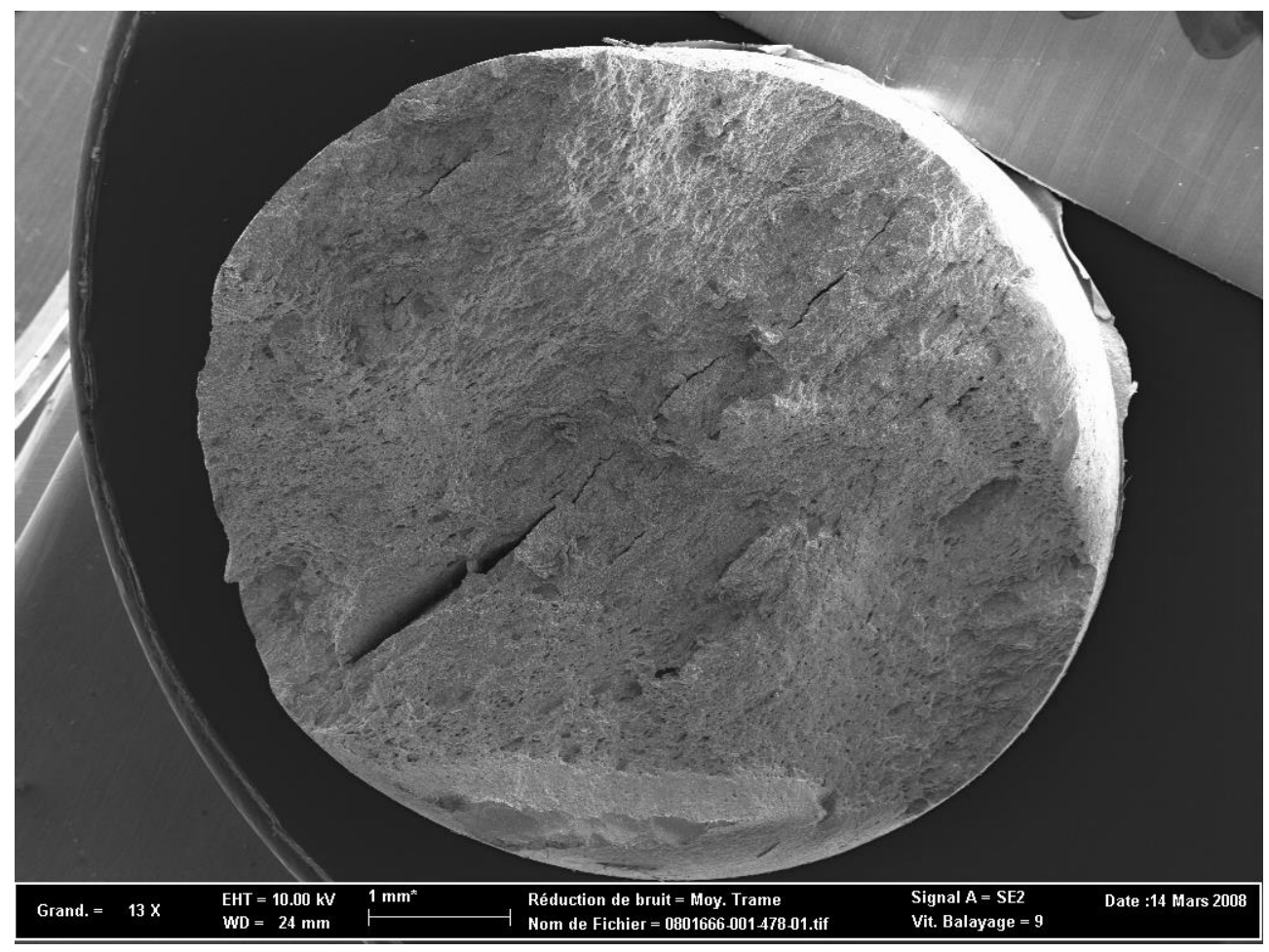

(a)

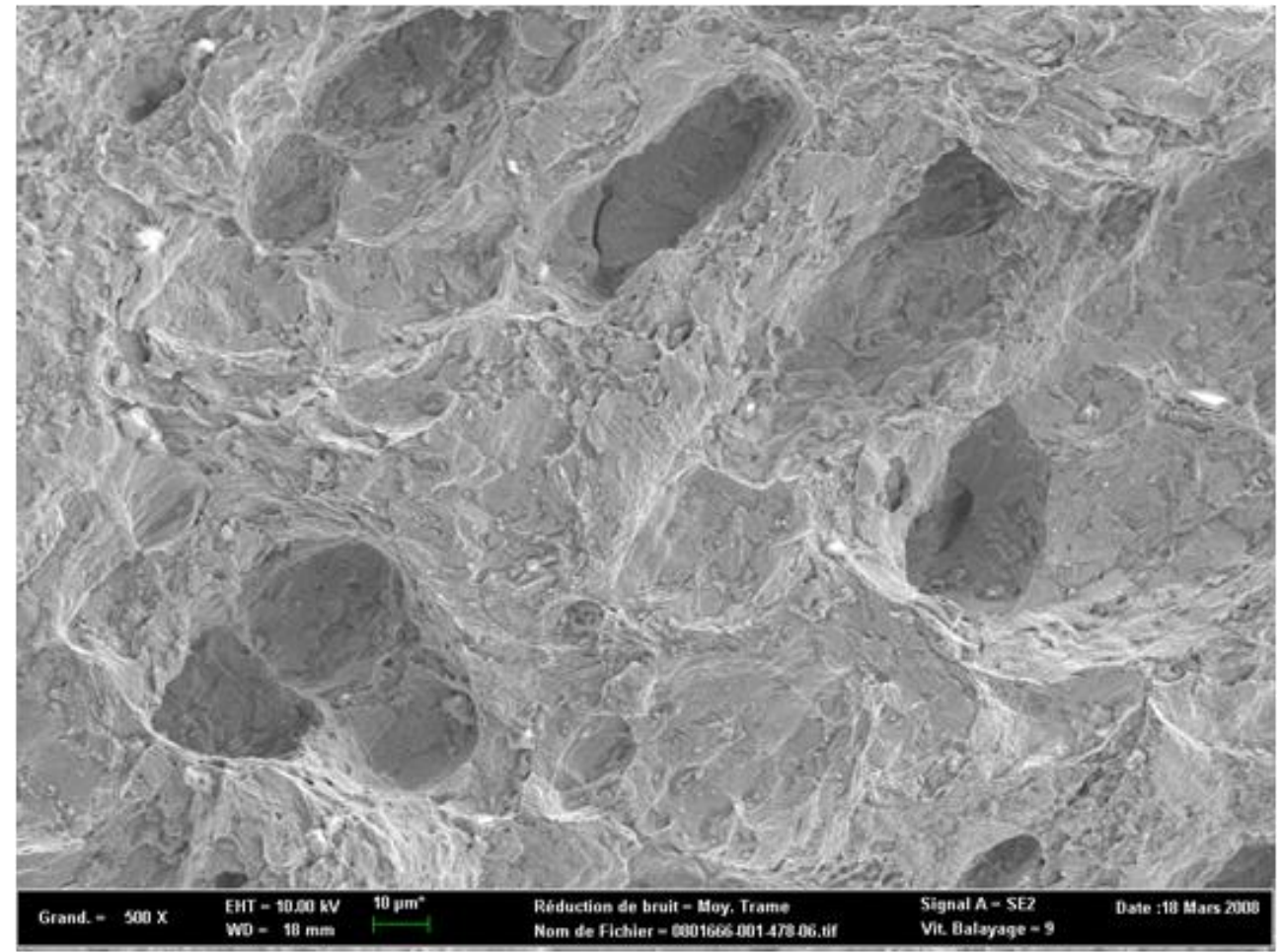

(b)

Figure 17: Fracture surface of $\mathrm{X} 65$ sour service steel after testing at $\mathrm{pH} 4.5$ and 1 bar H2S, with $90 \%$ YS applied load. Low (a) and high (b) magnification. 


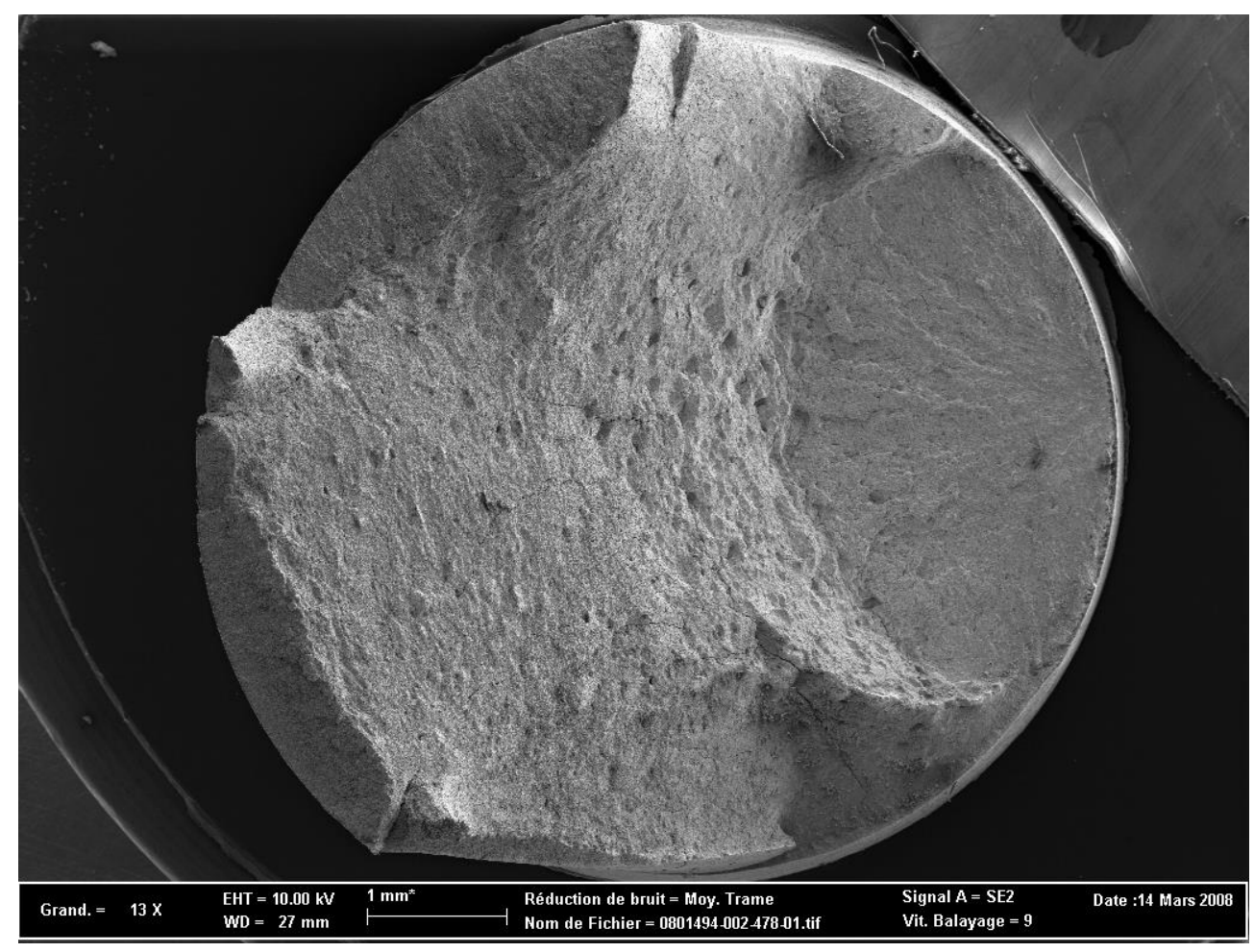

(a)

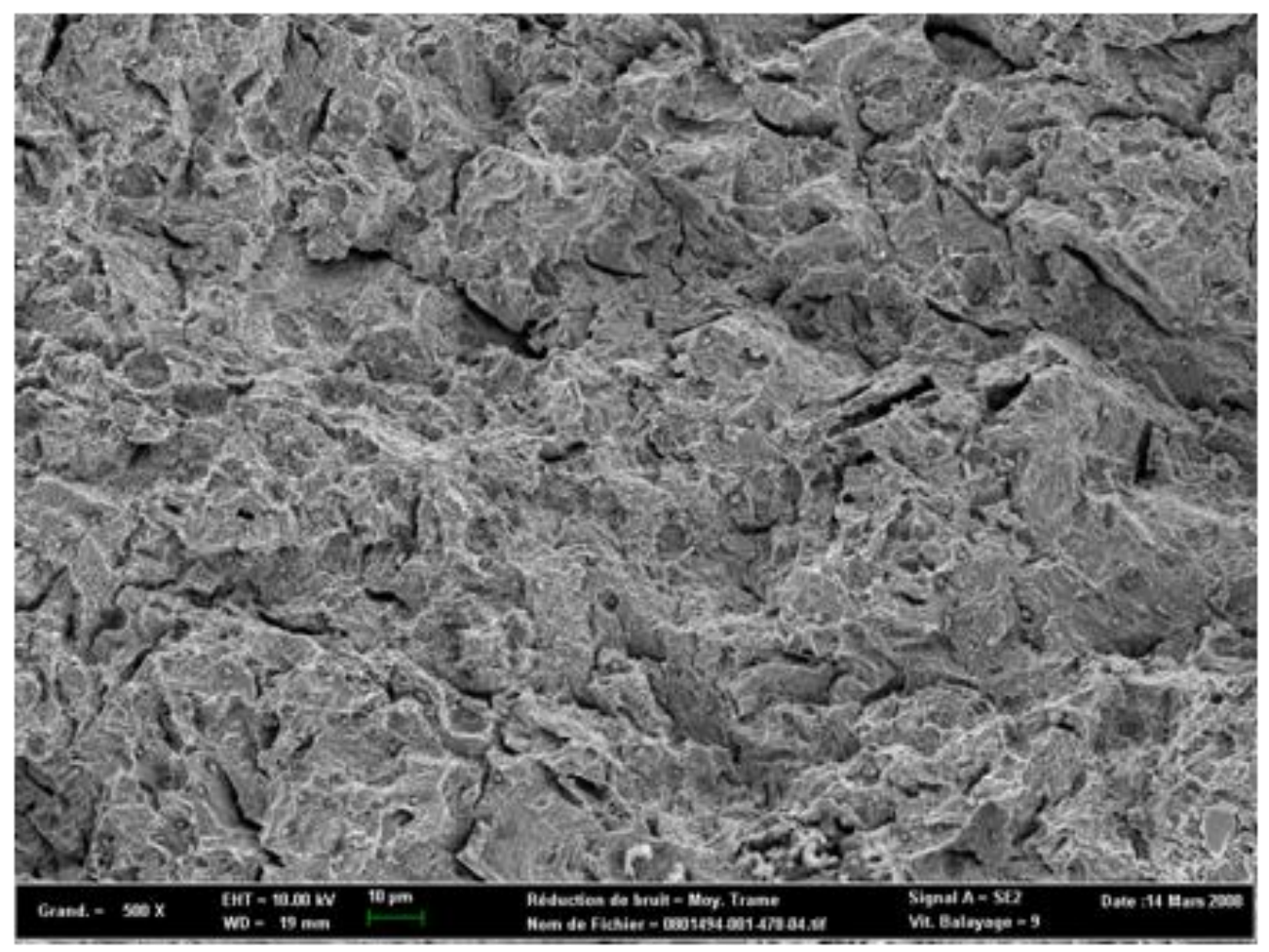

(b) 


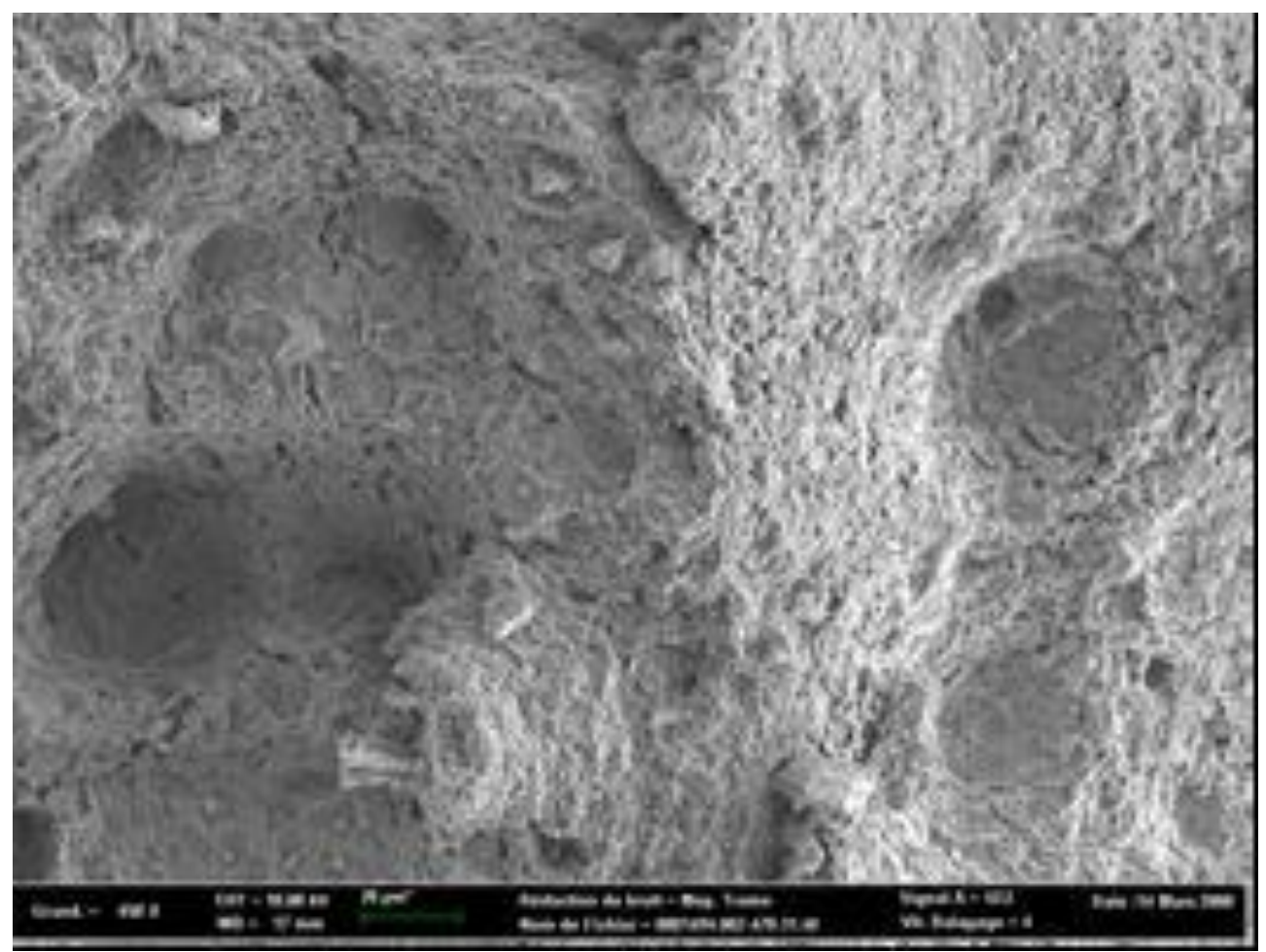

(c)

Figure 18: Fracture surface of $\mathrm{X} 65$ sour service steel after testing at $\mathrm{pH} 4.5$ and 1 bar $\mathrm{H} 2 \mathrm{~S}$, with $90 \%$ YS applied load. Low magnification (a) and high magnification observation of the circular brittle area (b) and of the $45^{\circ}$ ductile area (c). 